\title{
Country and Industry Dynamics in Stock Returns
}

\author{
Luis Catão \\ Research Department, \\ International Monetary Fund \\ Washington D.C. \\ Allan Timmerman \\ Department of Economics \\ University of California San Diego \\ and CEPR
}

This draft: February 20, 2003

\begin{abstract}
A perennial question in international finance is to what extent stock returns are influenced by country-location as opposed to industry-affiliation factors. This paper develops a novel methodology to measure these effects, in which portfolios mimicking "pure" country and industry factors are first constructed and their joint dynamics then modeled as regime-switching processes. Estimation using global firm level data allows us to identify well-defined volatility states over the past thirty years and shows that the contribution of the industry factor becomes systematically more prominent during high global volatility states, while the country factor contribution declines. Using the model's estimates we find that portfolio diversification possibilities vary considerably across economic states.
\end{abstract}




\section{Introduction}

A much-debated question in international finance is the extent to which firms' stock returns are influenced by country-location as opposed to industry-affiliation factors. Following Heston and Rouwenhorst (1994, 1995), a large literature has sprung up in recent years trying to measure the relative importance of these two effects. The standard approach consists of estimating cross-sectional regressions of individual firms' stock returns on a set of country and industry dummies, so that the coefficients on the dummies are interpreted as "excess-returns" associated with country or industry-affiliation relative to a perfectly diversified world portfolio. By and large, this literature has concluded that the country factor explains most of the cross-sectional variation in stock returns (Beckers et al., 1996; Griffins and Karolyi, 1998; Rouwenhorst, 1998; Serra, 2000), though its importance appears to have been waning in recent years relative to that of the industry factor, likely reflecting global financial integration (Baca et al., 2000; Brooks and Catão, 2000; Cavaglia et al. 2000).

Extant results have been based on time-series averages of the explanatory power of industry and country dummies in each cross-section, computed over arbitrarily specified (fixed or rolling) time windows. Implicit in this approach is the assumption that the factors driving country and industry-affiliation effects either remain constant over time or, at most, change very gradually. However, there are reasons to expect otherwise. For instance, policies that influence country risk are well-known to display discrete changes, and the emergence of new industries (such as information technology) can change the dynamics of the data generation process behind industry-affiliation effects. Indeed, the presence of such discrete and persistent changes is a well-known possible cause of business cycle asymmetries in macroeconomics (Hamilton, 1989) and also a much acknowledged source of non-linearities in asset risk and volatility clustering in financial data (Pagan and Schwert, 1990; Harvey, and Zhou, 1993). This suggests the need for greater flexibility in modeling the dynamics of country and industry effects.

This paper advances an alternative, dynamically richer framework to model such effects. It proposes a two-stage estimation method where in the first stage cross-sectional regressions are used to form country and industry portfolio returns. The dynamics of the returns on the various country and industry portfolios is then modeled as regime-switching processes in a second stage. The benefits of using cross-sectional regressions to form country and industry portfolios is twofold: first, it can be applied to large unbalanced panels; secondly, it reduces the number of time-series to manageable dimensions which permit the modeling of their joint dynamics as regime-switching processes, which are likely to provide a more accurate characterization of the (possibly nonlinear) dynamics of common factors in portfolio returns.

${ }^{1}$ See Timmermann (2000) and Perez-Quiros and Timmermann (2001) for a discussion of this point. 
The proposed two-stage approach builds on a long tradition in empirical finance, following the Fama and MacBeth (1973) method for testing asset pricing models. In their study, cross-sectional regressions are used to estimate risk premia on a variety of risk factors (including market exposure) in a first stage, whereas time-series averages and risk-premium standard errors are used to test their statistical significance in a second stage. The main difference between the Fama-MacBeth and our method lies in the second stage regressions where we do not simply consider the unconditional average returns on the various country and industry factors, but model their joint dynamics. Specifically, the time-series model we consider allows for different 'regimes' in portfolio returns, where each industry or country has a fixed (time-invariant) mean and variance within a particular regime. By allowing these parameters to vary across regimes and assuming that next period's regime is never known in advance, the model is capable of capturing complex country and industry factor dynamics which may have been overlooked in previous studies.

There are several advantages to our approach. By allowing the underlying volatilities and correlations to be driven by a discrete state variable that can switch from one period to the next, we achieve more of what Solnik and Roulet (2000) refer to as an 'instantaneous measure' of the correlation and volatility levels. Furthermore, to capture the possibility that risk characteristics of the separate country, industry and global component change at different frequencies, we allow shifts in these components to be driven by different discrete state variables displaying different degrees of persistence.

Using this framework, our paper addresses the following questions. First, does the "stylized fact" that country factors dominate industry-affiliation effects in fact hold uniformly over time and across economic states? Or, does it result from a type of dynamic misspecification stemming from the use of the standard single-regime linear model? Second, what is the strength of the various return correlations within the different regimes (if more than one) and the typical "persistence" of such states? Third, how much of the excess return of traditional country and industry portfolios is explained by 'pure' country and 'pure industry' factors, respectively? Fourth, how much does the global return component (which could be loosely viewed as a common "world" business cycle factor) vary over time and across economic states and how does this affect the correlations between country- and industry portfolios? Answers to these questions obviously have important implications for international risk management.

The main results are as follows. First, we find very strong evidence of nonlinear dynamic dependencies in both industry and country returns, suggesting that the dynamic 'mixtures of normals' model underlying the Markov-switching approach offers many advantages in terms of modelling global stock returns. In particular, specification tests reject (at the one percent significance level) the null of a single state model for 10 of the 13 advanced countries comprising our sample, and for 10 out of 11 industries (using the standard FTSE classification). 
Instead, we find evidence of two distinct states characterized by very different volatilities of stock returns, with the global high volatility regime tending to be less persistent than the low volatility regime. Second, once we model the nonlinear dynamics jointly across blocks of industry portfolios, we find a clear common nonlinear dynamic component from the industry return series, with industry volatility increasing relative to country volatility from the late 1990s. This points to the growing prominence of global industry effects alluded to in the recent literature. Third, we identified high and low volatility regimes in the vast majority of individual country portfolios. However, we could not identify similar states in the common time-series component in the volatility of the country return series, suggesting that country effects continue to be more heterogeneous than industry effects.

The remainder of the paper is structured as follows. Section 2 lays out the econometric methodology, while section 3 discusses the data. Empirical results are presented in section 4. Section 5 presents results from variance decompositions. Section 6 considers implications for global portfolio diversification while Section 7 summarizes the main findings.

\section{Econometric Methodology}

While an obvious approach to estimating the dynamics of country and industry factors in stock returns would be to estimate the various country and industry parameters jointly in a dynamic panel, this is not a feasible option when using large cross-sections of firm level data. Such panels comprise thousands of individual stock returns and tend to be highly unbalanced due to the fact that some firms die while others are "born" at some point within any reasonably long time series on stock return data.

Here we present an alternative approach to this problem which does not entail loosing information contained in the time series dynamics of individual country or industry stock return series nor in the whole cross-sectional dimension of the data. Specifically, we propose a two-stage approach where, in the first stage, we follow Heston and Rouwenhorst (1994, 1995) and extract the industry and country returns for a given time period through crosssectional regressions in which each firm's stock returns is defined as:

$$
R_{i j k t}=\alpha_{t}+\beta_{j t}+\gamma_{k t}+\varepsilon_{i t}
$$

Here $R_{i j k t}$ stands for the return at time $t$ of the $i^{\text {th }}$ firm which belongs to the $j^{\text {th }}$ industry and the $k^{\text {th }}$ country.

Thus, equation (1) simply states that a firm's stock returns at time $t$ is the sum of a global factor $\alpha_{t}$ common to all firms, an "excess" return $\beta_{j t}$ owing to the firm's belonging to industry $j$, an "excess" return $\gamma_{k t}$ associated with the firm's location in country $k$, and an 
idiosyncratic firm-specific factor $\varepsilon_{\mathrm{it}}$. Assuming that there are $J$ industries and $K$ countries, equation (1L can be written as:

$$
R_{i j k t}=\alpha_{t}+\sum_{j=1}^{J} e_{i j \beta} \beta_{j t}+\sum_{k=1}^{K} e_{i k \gamma} \gamma_{k t}+\varepsilon_{i t}
$$

Here $e_{i j \beta}$ is a dummy variable defined as 1 for the $i$ th firm's industry and zero otherwise, while $e_{i k \gamma}$ is a dummy defined as 1 for the $i$ th firm's country and zero otherwise.

Since each firm can only belong to one industry and one country at a time, the various industry dummies in (2 2 vill be orthogonal to each other within the cross-section. Likewise, the various country dummies will also be orthogonal to each other. However, equation (2) cannot be estimated as it stands because of perfect multicollinearity among the regressors. This is because every company belongs to both an industry and a country, whereas the industry and country effects can only be measured relative to a benchmark. To resolve this identification issue, we follow the literature in imposing the restriction that the weighted sum of industry and country effects equals zero at every point in time, so that the industry and country effects are estimated as deviations from the intercept $\alpha$ :

$$
\begin{aligned}
& \sum_{j=1}^{J} \beta_{j} \sum_{i=i}^{N} e_{i j \beta} x_{i}=\sum_{j=1}^{J} \beta_{j} w_{j}=0 \\
& \sum_{k=1}^{K} \gamma_{k} \sum_{i=1}^{N} e_{i j \gamma} x_{i}=\sum_{k=1}^{K} \gamma_{k} v_{k}=0 .
\end{aligned}
$$

Here $N$ is the total number of firms in a given period. Equation (2) can then be estimated subject to the restrictions (3) and (4). As in several of the studies referred to above, we estimate (2/ hising weighted least squares. In doing so, each stock return is weighted by its beginning-of-period share $x_{\mathrm{i}}$ of the global stock market capitalization (computed as a sum of the market capitalization of all the $N$ firms comprising the cross-section), so that $w_{\mathrm{j}}$ corresponds to the market capitalization of industry $j$ as a share of the global market, while $v_{\mathrm{k}}$ is the market capitalization of country $k$ as a share of the global market.

The weighted least squares estimates of the parameters in (2) subject to (3) and (4) yields orthogonal excess return vectors for the various $J$ industries and $K$ countries for every $t$. An advantage of constructing country and industry portfolios this way is that the number of firms at each cross-section can vary and yet a balanced panel of portfolios of country and industry specific excess returns can be formed, effectively summarizing the relevant information from the original unbalanced panel.

Defining excess return vectors as 


$$
\boldsymbol{\beta}_{t}=\left(\begin{array}{l}
\beta_{1 t} \\
\beta_{2 t} \\
\vdots \\
\beta_{J t}
\end{array}\right), \quad \boldsymbol{\gamma}_{t}=\left(\begin{array}{c}
\gamma_{1 t} \\
\gamma_{2 t} \\
\vdots \\
\gamma_{K t}
\end{array}\right),
$$

we can re-write equation (2) \&s:

$$
R_{i j k t}=\alpha_{t}+\mathbf{e}_{i \beta}^{\prime} \boldsymbol{\beta}_{t}+\mathbf{e}_{i \gamma}^{\prime} \gamma_{t}+\varepsilon_{i t} .
$$

where $\mathbf{e}_{i \beta}$ is a $J \times 1$ vector of zeros with a one in the $i$ th firm's industry, while $\mathbf{e}_{i \gamma}$ is an $K \times 1$ vector of zeros with a one in the $i$ th firm's country.

\subsection{Country- and Industry-specific Return Dynamics}

While the earlier literature has not attempted to link the individual industry $\left(\boldsymbol{\beta}_{t}\right)$ and country components $\left(\gamma_{t}\right)$ over time, we will allow for such dependencies in these components in a flexible manner which does not impose linearity or serial independence a priori. In particular, we follow the large empirical literature that has documented the presence of persistent 'regimes' in a variety of financial time series. Ang and Bekaert (2002), Driffill and Sola (1994), Gray (1996), Hamilton (1988)) find evidence of multiple states in the dynamics of interest rates, while Ang and Bekaert (2001), David and Veronesi (2001), Guidolin and Timmermann (2002), Perez-Quiros and Timmermann (2000), Turner, Starz and Nelson (1989) and Whitelaw (2001) provide evidence for stock market returns. Typically these states capture periods of high and low volatility in returns. Most of these papers model states in univariate return series 9 in pairs of returns (e.g., Ang and Bekaert (2001), Perez-Quiros and Timmermann (2000)).

Specifically, we assume that there are separate "state" variables driving returns on the global, industry, and country portfolios labeled $s_{\alpha t}, s_{\beta_{j} t}, s_{\gamma_{k} t}$. We show in the empirical section that the data justifies this assumption. If, furthermore, these state processes are industry and country specific, we can write returns on the global, industry and country portfolios as follows:

\footnotetext{
${ }^{2}$ Guidolin and Timmermann (2002) also consider a model for the joint dynamics of returns on small firms, large firms, bonds and T-bills.
} 


$$
\begin{aligned}
& \alpha_{t}=\mu_{\alpha s_{o t}}+\sigma_{\alpha s_{\alpha t}} \varepsilon_{\alpha t}, \\
& \beta_{j t}=\mu_{\beta_{j} s_{j i t}}+\sigma_{\beta_{j} s_{\beta j t}} \varepsilon_{\beta j t}, \\
& \gamma_{k t}=\mu_{\gamma_{k} s_{k t t}}+\sigma_{\gamma_{k} s_{\gamma t}} \varepsilon_{\gamma k t .}
\end{aligned}
$$

Suppose, for example, that there are two states for the global return process so $\mathrm{s}_{\alpha \mathrm{t}}=1$ or $\mathrm{s}_{\alpha \mathrm{t}}=2$. Then the mean return on the global return component in any given period, $t$, is either $\mu_{\alpha 1}$ or $\mu_{\alpha 2}$, while its volatility is either $\sigma_{\alpha 1}$ or $\sigma_{\alpha 2}$. Similarly, if the $j$ th industry state variable can take two values, $\mathrm{s}_{\beta \mathrm{jt}}=1$ or $\mathrm{s}_{\beta \mathrm{jt}}=2$, then the $j$ th industry's mean return at time $t$ is either $\mu_{\beta \mathrm{j} 1}$ or $\mu_{\beta \mathrm{j} 2}$ while its volatility is either $\sigma_{\beta \mathrm{j} 1}$ or $\sigma_{\beta \mathrm{j} 2}$.

One could of course impose a constraint that the mean return was the same in the two states in which case our model would simply capture time-varying volatility. However, on theoretical grounds we would expect the mean returns to be different in the high and low volatility state, so we allow the mean parameters to be state-dependent.

How the state processes alternate between states is obviously important. We follow conventional practice and assume constant state transition probabilities for the global return process as well as for the individual country and industry return processes: ${ }^{3}$

$$
\begin{aligned}
& \operatorname{Pr}\left(S_{\alpha t}=s_{\alpha} \mid S_{\alpha t-1}=s_{\alpha}\right)=p_{\alpha s_{\alpha} s_{\alpha}}, \\
& \operatorname{Pr}\left(S_{\beta j t}=s_{\beta_{j}} \mid S_{\beta_{j} t-1}=s_{\beta j}\right)=p_{\beta j s_{\beta j} s_{\beta j}}, \\
& \operatorname{Pr}\left(S_{\gamma k t}=s_{\gamma k} \mid S_{\gamma k t-1}=s_{\gamma k}\right)=p_{\gamma k s_{\gamma k} s_{\gamma k}} .
\end{aligned}
$$

Here $p_{\alpha 11}$ is the probability that the global return process remains in state 1 if it is already in this state, $p_{\beta j 11}$ is the probability that the $j$ th industry state variable remains in state 1 and so forth. This means that the regimes are generated by a discrete state homogenous Markov chain. We will be interested in studying the state probabilities implied by our models given the current information set, $\Gamma_{t}$, which comprises all information up to time $t$, i.e., $\pi_{s \alpha t}=\operatorname{Pr}\left(S_{\alpha t}=s_{\alpha} \mid \Gamma_{t}\right), \pi_{s \beta_{j} t}=\operatorname{Pr}\left(S_{\beta_{j} t}=s_{\beta_{j}} \mid \Gamma_{t}\right), \pi_{s \gamma_{k} t}=\operatorname{Pr}\left(S_{\gamma_{k} t}=s_{\gamma} \mid \Gamma_{t}\right)$, where $\Gamma_{\mathrm{t}}$ is the current information set containing (at a minimum) returns up to time $t$. As we shall see in the empirical section, the time series of these probabilities, extracted from the data, provide information about high and low volatility states.

\footnotetext{
${ }^{3}$ While it is possible to further extend the model by allowing for time-varying state transition probabilities, c.f., Gray (1996), we do not consider this complication of our model here. We keep the model relatively simple to facilitate generalization of the model to the case with multiple industries or countries, where the number of parameters already is rather large.
} 
Finally, we assume that the innovation terms, $\varepsilon_{\alpha \mathrm{t}}, \varepsilon_{\beta \mathrm{jt}}$ and $\varepsilon_{\gamma \mathrm{kt}}$ are normally distributed. Notice that this means that the return process will be a mixture of normal random variables. This is a distribution that is capable of accommodating features such as skews and fat tails that are frequently found in financial return distributions.

by

Under this model, the return on the $i$ th company in industry $j$ and country $k$ is given

$$
R_{i j k t}=\mu_{\alpha s_{\alpha t}}+\mu_{\beta_{j} s_{\beta j t}}+\mu_{\gamma_{k} s_{\gamma k t}}+\sigma_{\alpha s_{\alpha t}} \varepsilon_{\alpha t}+\sigma_{\beta_{j} s_{\beta j t}} \varepsilon_{\beta j t}+\sigma_{\gamma_{k} s_{\gamma k t}} \varepsilon_{\gamma k t}+\varepsilon_{i t}
$$

Clearly each stock will be affected by separate global, industry and country regimes plus an idiosyncratic error term so the model provides a flexible characterization of returns on individual stocks.

\subsection{Common Nonlinear Components}

The above model assumes that the state processes or "regimes" underlying returns on the industry and country portfolios are different for different countries and industries. This represents a natural starting point insofar as many factors underlying these portfolios' risk and return characteristics could well be country- and industry specific.

However, it is possible that the state variable driving the industry and country returns shares an important common component across industries and country returns. This could be induced, for example, by an oil shock to the extent that the latter tends to have a large differential effect across industries and a far more homogenous effect across countries. Similarly, there may be common institutional shocks that spread along country lines as opposed to industry lines. One example is the growing worldwide consensus to keep inflation at bay and the associated institutional changes in central bank mandates- a factor which has been deemed to help explain the decline of world inflation and the concomitant upward trend in global asset prices since the mid-1980s (IMF, 2000).

If such dependencies exist across countries or across industries, a more efficient way to gain information about the underlying state variable is to estimate a multivariate regimeswitching model jointly for several portfolios. To account for the possibility that a common state factor is driving the individual industry returns on the one hand and the individual country returns on the other hand, we consider the following model

$$
\begin{aligned}
& \alpha_{t}=\mu_{\alpha s_{\alpha t}}+\varepsilon_{\alpha s_{\alpha t}}, \\
& \boldsymbol{\beta}_{t}=\mu_{\beta s_{\beta t}}+\varepsilon_{\beta s_{\beta t}}, \\
& \boldsymbol{\gamma}_{t}=\boldsymbol{\mu}_{\gamma s_{\gamma t}}+\varepsilon_{\gamma s_{\gamma t}},
\end{aligned}
$$


where $\mu_{\alpha s_{\alpha t}}$ is the scalar global mean return in state $s_{\alpha t}, \mu_{\beta s_{\beta t}}$ is a J-vector of industry means in state $s_{\beta t}, \boldsymbol{\mu}_{\gamma_{\gamma t}}$ is a K-vector of country means in state $s_{\gamma t}$. Furthermore, the innovations to returns have zero mean with state-specific variances $\varepsilon_{\alpha s_{\alpha t}} \sim\left(0, \sigma_{\alpha s_{\alpha t}}^{2}\right) \varepsilon_{\beta s_{\beta t}} \sim\left(0, \Omega_{\beta s_{\beta t}}\right)$, $\varepsilon_{\gamma s_{\gamma t}} \sim\left(0, \Omega_{\gamma s_{\gamma t}}\right)$, where $\sigma_{\alpha s_{\alpha t}}^{2}$ is the scalar variance of global return in state $s_{\alpha t}, \Omega_{\beta s_{\beta t}}$ is the $J x J$ variance-covariance matrix of industry returns in state $s_{\beta t}, \Omega_{\gamma s_{\gamma t}}$ is the $K x K$ variancecovariance matrix of country returns in state $s_{\gamma t}$.

State transitions for this common factor case are still assumed to be time-invariant:

$$
\begin{aligned}
& \operatorname{Pr}\left(S_{\alpha t}=s_{\alpha} \mid S_{\alpha t-1}=s_{\alpha}\right)=p_{\alpha s_{\alpha} s_{\alpha}}, \\
& \operatorname{Pr}\left(S_{\beta t}=s_{\beta} \mid S_{\beta t-1}=s_{\beta}\right)=p_{\beta s_{\beta} s_{\beta}}, \\
& \operatorname{Pr}\left(S_{\gamma t}=s_{\gamma} \mid S_{\gamma t-1}=s_{\gamma}\right)=p_{\gamma s_{\gamma} s_{\gamma}} .
\end{aligned}
$$

The regime switching model is fully specified by the state transitions (10), the functional form of the return equation (9) and the assumed "mixture of normals" density. However, estimation of the model is complicated by the fact that the state variable is unobserved or latent. We deal with this by obtaining maximum likelihood estimates based on the EM algorithm.

A major advantage of our common nonlinear factor approach is that it allows us to extract volatility estimates of portfolio strategies involving an arbitrary number of countries or industries in addition to the global component. As explained by Solnik and Roulet (2000), the standard way to capture time-variation in market volatility and correlations is by using a fixed-length rolling window of, say, 36 or 60 months of returns data and estimate crosscorrelations for pairs of countries (c.f. Solnik, Boucrelle and Le Fur, 1996). This approach has three major disadvantages compared to our approach. First, since the rolling window does not rely on the full data sample, it is likely to lead to imprecise estimates of volatilities and correlations which typically require relative large data samples for precise estimation. Second, by construction as they present moving averages of volatilities, rolling window estimates cannot capture relatively short-lived volatility bursts that may be economically interesting and important to investors' risk management. Third, rolling window estimates provide unconditional estimates of volatilities and correlations and do not exploit any dynamic structures in the covariance of portfolio returns.

In contrast, notice the richness of the dynamics in our model: for a given state the mean and variance of returns are constant, as are the correlations between various industry (country) portfolios. However, as the state probabilities vary over time, the conditional correlation, mean and variances of returns are allowed to fluctuate. Using the ex-ante state probabilities, the model allows for time-varying expected returns and measures of risk. The mechanism for generating such time-variations arises because of the time-varying state 
probabilities. The general model also captures the correlations between returns on different country and industry portfolios.

It is of course possible to construct an even more restrictive version of (9) that assumes the global, industry and country factors are driven by the same state process. However, as we shall see in the empirical section, the data does not support such a specification. This is, perhaps, unsurprising since the sources of discrete changes (economic policy, technology shocks etc) are likely to be quite different at these levels.

\section{Data}

The data cover monthly total returns and market capitalizations for up $t \mathrm{p} 3,951$ firms in developed stock markets over the period February 1973 to February 2002. Country coverage spans Australia, Belgium, Canada, Denmark, France, Germany, Ireland, Italy, Japan, Netherlands, Switzerland, the UK and the US. While data are available for other national stock markets, estimation of the econometric model for a significantly larger number of countries becomes unfeasible and probably redundant in any case, since the group of countries considered is sufficiently representative of the global stock market (see below). Firms in these 13 countries are grouped into one of 11 FTSE industry sectors: resources, basic industries, general industries, cyclical consumer goods, non-cyclical consumer goods, cyclical services, non-cyclical services, utilities, information technology, financials and others. While some recent papers argue in favor of a finer industry disaggregation, the level

\footnotetext{
${ }^{4}$ Monthly total returns are computed in local currency using data from Datastream/Primark. The return calculation assumes immediate reinvestment of dividends. These local currency returns are converted to U.S. dollars using end-of-month spot exchange rates. The beginning-of-month stock market capitalizations are converted into U.S. dollars using the beginning-of-month dollar price of one unit of local currency. Expressing all returns and market cap data in US dollars implicitly reflects the perspective of a currency unhedged equity investor whose objective is to maximize US dollar returns. It is important to note, however, that since changes in equity returns far overwhelm those associated with currency fluctuations, expressing returns and market caps in the distinct national currencies should not change the thrust of the results, as previous studies have found (Griffin and Karolyi, 1998; Brooks and Catão, 2000). Developing countries were excluded from the sample altogether because none of these countries had data stretching back to 1973 and most of them only have data available from the late 1980s/early 1990s, so that their inclusion would probably distort the representativeness of the sample over time and, in any case, entail too short time series for the estimation of Markov-switching processes for the respective country portfolios.

${ }^{5}$ These broad FTSE classification can be further broken down as follows: Resource industries comprise mining, oil and gas; basic industries comprise chemicals, construction and building materials, forestry and paper, and steel and other metals; general industries encompass aerospace \& defense, diversified industrials, electronic \& electrical equipment, engineering \& machinery; cyclical consumer goods comprise automobile, household goods \& textiles; non-cyclical consumer goods include beverages, food producers \& processors, health, packaging, personal care $\&$ household
} 
of disaggregation used here is sufficient not only because it follows the traditional industry breakdown used by portfolio managers and much of the academic literature, but also because it clearly distinguishes new industries which appear to have distinct time series dynamics of stock returns (such as information technology - see Brooks and Catão, 2000) from "old economy" industries.

A desirable feature of this data is that it be a realistic and unbiased representation of the global stock market. As of December 1999, the total capitalization of the sample comes to $\$ 26.3$ trillion or 80 percent of stock market capitalization in advanced countries as measured by the IFC yearbook and 73 percent of the world market capitalization (i.e. including developing countries). Coverage deteriorates somewhat towards the beginning of the sample but because the data comprises the largest and internationally most actively traded firms in key markets such as the United States, Japan, and the United Kingdom throughout, the sample can be deemed as quite representative from the viewpoint of the global investor. It should be noted, however, that the deterioration in coverage reflects two deficiencies of the data set. First, it is subject to survivorship bias, meaning that only firms surviving over the full sample period are covered. No doubt this bias is important, especially in the context of global shocks such as that of the 1987 crash and the virulent recession of the early 1990s in Europe and Japan. But this problem is partly offset by the fact that the data omit a large number of small firms which typically face greater bankruptcy risks and whose influence in a market capitalization weighted world portfolio is low in any case. A potentially more serious flaw of the data is that it includes only post-merger companies, dropping companies that go into the merger. It is possible that this may bias the estimates in favor of finding more pronounced global industry effects in more recent years in the sample.

On the positive side, our sample stretches over a much longer time period than those in the studies referred to in the introduction, and this is a crucial advantage required for estimation of regime switching processes with some degree of precision. As we shall see, most regimes tend to be quite persistent so identifying them requires a time series as long as that considered in our study. No single country is represented by less than 28 firms on

products, phamarceuticals, tobbaco; cyclical services comprise distributors, general retailers, leisure, entertainment $\&$ hotels, media $\&$ photography, restaurants, pubs $\&$ breweries, support services, and transport; non-cyclical services comprise food \& drug retailers, telecommunication services; utilities comprise electricity, gas distribution, and water; financials comprise banks, insurance, life insurance, investment companies, real estate and specialty \& other finance; information technology comprise information technology hardware and software \& computer services; other industries include nonclassified miscellaneous.

${ }^{6}$ While Griffin and Karolyi (1998) note that a finer industry disaggregation may yield a more accurate measure of industry effects, their main result - the dominance of country-specific effects hardly changes with the move to a finer industry breakdown (they have nine broad industry categories and 66 more disaggregated industries). Meanwhile, Heston and Rouwenhorst's (1995) results are based on seven broad industry categories. 
average (Ireland and Denmark) and, in the case of large economies such as the US and Japan, coverage approaches 1,000 firms towards the end of the sample from a minimum of 377 firms at the beginning of the sample (February 1973). This reasonably large time series and cross-sectional dimension of the data probably eliminates any significant distortion in the econometric results arising from the deficiencies mentioned above. Moreover, to the extent that much of our analysis focuses on the variance of stock returns rather than on their mean values, the main results are unlikely to be vulnerable to the traditional survivorship bias problem.

\section{Empirical Results}

This section first presents the full-sample results for the returns on the individual industry- and country portfolios considered in our analysis. These results serve as a benchmark for the subsequent dynamic analysis and also allow us to relate our findings to the extant literature. Next we model nonlinear dynamics in the individual country- and industry portfolios. Finally we consider the presence of common dynamic components in the country and industry returns.

Table 1 presents some summary statistics for the distribution of the country-, industry and world portfolios. All country and industry portfolio returns are measured in excess of the world portfolio so the mean returns on these portfolios are close to zero on average. ${ }^{7}$ The standard deviations average 4.89 percent per month for the country portfolios and 2.96 percent for the industry portfolios, thus verifying the finding in the literature that, on average, country factors matter more than industries for explaining variations in stock returns. Country portfolios tend to be slightly more strongly positively skewed than the industry portfolios while, interestingly, returns on the global portfolio are not skewed. There is also strong evidence of excess kurtosis in most of the portfolios. Accordingly, Jarque-Bera test statistic for normality rejected the null of normally distributed returns for all portfolios except

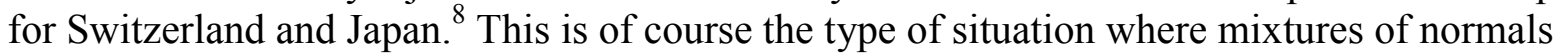
may better be able to capture the underlying return distribution.

\subsection{Nonlinear Dynamics in Returns}

Previous studies of country- and industry effect in international stock returns have been based on the assumption of a single state, so it is important to investigate the validity of this assumption. To determine whether a regime switching model is appropriate for our analysis, we first verify that two or more states characterize the return generating process of

\footnotetext{
${ }^{7}$ The only reason the averages are not exactly equal to zero is that we are reporting arithmetic averages whereas the world portfolio is based on capitalization-weighted returns.

${ }^{8}$ Results of the Jarque-Bera test statistics are available from the authors upon request.
} 
the individual industry and country portfolios. For this purpose we report the outcome of the statistical test proposed by Davies (1977). Standard likelihood ratio tests do not account for the problem associated with unidentified nuisance parameters under the null hypothesis of a single regime. The Davies test takes this problem into account. The results are shown in Table 2. For 10 out of 13 countries and 10 of 11 industries, the null of a single state is rejected at the $1 \%$ critical level. Linearity is also strongly rejected for the global portfolio. Hence there is overwhelming evidence of nonlinear dynamics in the form of multiple regimes in country, industry and global returns.

These test results suggest that there are at least two regimes in the vast majority of return series. However they do not tell us if two, three or even more states are needed to model the return dynamics. To choose among model specifications with multiple states, Table 3 reports the results of three standard information criteria that are designed to trade off fit (which automatically grows with the number of parameters and thus with the number of underlying states) against parsimony (as measured by the total number of parameters). We report results using the Akaike (AIC), the Schwarz Bayesian (BIC) and the Hannan-Quinn (HQ) information criteria. For the 13 country portfolios, the three criteria unanimously point to a single state for Canada and Switzerland and three states for the UK, and at least two of the above criteria suggest that stock returns in all other countries are better modeled as a twostate process.

Turning to the industry portfolios, the results are even more homogenous, with the BIC and HQ criteria selecting a two-state model for 9 industries out of 11 . At the same time, all three criteria indicate that stock returns in Resources are best captured through a threestate model. Only for cyclical services is there considerable difference - the BIC and HQ choosing a single-state model while the AIC selects a three-state specification. Finally, regarding the global portfolio, AIC and HQ choose a two-state specification, while the BIC marginally selects a single-state specification. Overall, therefore, the results in Table 3 strongly indicate the presence of two states in the dynamics of the various portfolio returns. Accordingly, the subsequent analysis is based on this specification.

\subsection{Country Return Dynamics}

Panel A of Table 4 shows the maximum likelihood estimates of the parameters of the two-state regime-switching model fitted to returns on the individual country portfolios for which there was evidence of multiple states, i.e. all countries except for Canada and Switzerland. The ordering of states is, of course, arbitrary so we stick to the convention of listing the state with the highest volatility as state 1 , while state 2 is the state with the lowest volatility. Using this convention, the first two columns in Table 4 show the volatility (standard deviation) estimates for the two states, while columns 3 and 4 provide the

\footnotetext{
${ }^{9}$ The finding of a single state for Canada and Switzerland is consistent with the Davies' tests in Table 2 which could not reject linearity for these two countries.
} 
estimated state transition probabilities $\mathrm{p}_{11}$ (the probability of staying in state 1 ) and $\mathrm{p}_{22}$ (the probability of staying in state 2) followed by the steady state probabilities (columns 5 and 6 ) and the average monthly duration of the two states (columns 7 and 8).

Differences between the volatility parameters of the two regimes are highly significant, both economically and statistically. 10 The average country volatility estimate is 7.1 percent per month in the high volatility state, almost twice the value in the low volatility state (3.6 percent per month). In all bar one country, Japan, the high volatility state has the lowest persistence. This is consistent with the notion that bursts of volatility do not last all that long. In some countries the duration of the high volatility state is very short. For example, for Belgium the high volatility state lasts less than three months on average, while the low volatility state has an average duration of more than 25 months. Countries that have volatility bursts of very short duration may generate mean returns that appear rather extreme in the high volatility state, in part because volatility is so high in this state and in part because the mean return estimate is based on relatively few observations. Fortunately the vast majority of countries have 'stayer probabilities' for the low volatility state that are well above $90 \%$. On average, across countries, the duration of the high volatility state is 16 months while it is 39 months for the low volatility state. As a consequence, as shown by the steady-state probabilities, an average of $70 \%$ of the time is spent in the low volatility state while $30 \%$ of the time is spent in the high volatility state.

To assist in the economic interpretation of the two regimes, Figure 1 plots for each country the smoothed probability of the high volatility state (state 1 ). The time-series properties are quite mixed, reflecting the well-known heterogeneity of country factors documented in the literature (more on this below). Nevertheless, clearly defined persistent states emerge in all countries but Japan and the Netherlands. Also noticeable in Figure 1 is a clear tendency towards a switch to the low volatility state in the last part of the sample for the US, UK, France, Germany, Australia and Denmark. As discussed further below, this lends credibility to the notion that the contribution from the country component to explaining stock return variations has recently declined in significance. Moreover, the results indicate that this decline occurred some time during the nineties, albeit not necessarily at the same time in all countries.

\subsection{Industry Return Dynamics}

${ }^{10}$ Although we are not primarily concerned with the mean return variation across states, the mean return computed across countries is estimated at 0.73 percent per month in the high volatility state and -0.26 percent in the low volatility state. One should not put too much into the mean estimates in the two states, however, since they are associated with considerable uncertainty, particularly for countries such as Belgium, Italy and Ireland where little time is spent in the high volatility state. 
As with the country portfolios, Table 4 shows that the difference between the volatility levels in the two states for the industry portfolios is also very large, with average industry volatility of 4.3 percent per month in the high volatility state and average volatility of 2.1 percent in the low volatility state. Despite this similarity, the dynamics of the low and high volatility regimes is quite different for the industry portfolios than for the country portfolios. In all industries except for Resources, the 'stayer' probability is higher in the low volatility state than in the high volatility state. For the industry portfolios both states are highly persistent with average stayer probabilities of 91 percent in the low volatility state and 94 percent in the high volatility state. The high volatility state is thus clearly more persistent for the industry portfolios than for the country portfolios. Consequently on average 39 percent of the time is spent in the high volatility state in the case of the industry portfolios. Again, the average duration of the low volatility state is more than twice as long as that of the high volatility state.

To assist with the economic interpretation of these results Figure 2 presents the smoothed probabilities of the high volatility state for the industries where multiple states were identified. The high volatility regimes of the industry portfolio returns are clearly more homogenous than the regimes identified for the country returns in Figure 1 - a result consistent with the findings of Heston and Rouwenhorst (1994) who also report that industry volatility is more uniform than country volatility. This similarity is all the more remarkable in the present context since each of the plots is based on univariate regressions and thus does not utilize information about returns in other industries. In most industries, the states persist for long periods of time and are very clearly separated by the data in the sense that the probability of the regime from which the returns data in a given month is drawn is almost always far from 0.5. In most industries the high volatility state emerged in 1986 and again from 1998 and onwards. There is also a tendency for common high volatility around 197475.

\subsection{A joint model of common components}

The extant literature seeks to answer how much country and industry effects matter "on average". The empirical results thus far have identified regimes that are specific to each industry or country portfolio. However, addressing the question of the overall importance of industry and country effects, requires studying common country and common industry effects. To do so, we next study a model in which there are separate regimes in the joint country and inthy joint industry portfolio returns. This yields a nonlinear dynamic common factor model.

${ }^{11}$ The vast majority of recent work on dynamic common factor models assumes a linear factor structure, see e.g. Stock and Watson (1999). We allow for nonlinear dynamics principally because of our interest in extracting common factors in the volatility of returns on various portfolios and also because of the strong empirical evidence of time-varying volatilities in stock returns. 
We do so by estimating joint regime switching models for the return series on the 13 country portfolios and 11 industry portfolios. To our knowledge, regime switching models on such large systems of variables have not previously been estimated jointly. The joint estimation of the parameters of a highly nonlinear model for such a large system is a nontrivial exercise.

Table 5 presents estimates of the transition probabilities and average state durations and the outcome of the Davies test for multiple states. Estimation results are shown in Table 6 which also presents results for the global portfolio. Since the joint country model has 210 parameters while the joint industry model has 156 parameters (most of which measures the covariance between industry returns in the two states), we do not report all the estimates and instead concentrate on the standard deviations.

Again, the null hypothesis of a linear model with a single state is strongly rejected for the country-, industry- and world models. The Davies test yields p-values below 0.001 for all models. All three information criteria supported a two-state model over the single-state model in the case of the joint industry and joint country models, while both the AIC and the HQ criterion supported the two-state specification over the one-state model for the global return model.

First consider the common country component. Table 5 shows that the two states identified in country returns have persistence parameters of 0.975 and 0.976 . With such high persistence parameters, the durations of the two states are very high at 40 and 42 months, respectively. Clearly this model is picking up long-lasting regimes in the common component of the country portfolios. The average volatility is around 4.9 percent in both states, so the states are no longer defined along high and low volatility, at least not on average. Even so, the volatility is markedly higher in the first state for the US. Average correlations across country portfolios are close to 0.1 in both states, although, again, for some countries there are some interesting differences. For example, the US has a small positive average correlation of 0.05 with other countries in state 1 (the high volatility state) and a large negative correlation (-0.33) with other countries in the low volatility state. 2 The implication of this is that the diversification possibilities for a US investor are reduced in the high volatility state, a finding consistent with much of the existing literature, c.f. Longin and Solnik (2001).

Very different results emerge from the parameter estimates for the joint industry model. In the low volatility state (state 2 ) the average volatility is 2.27 percent while it is more than twice as high in the high volatility state (4.67). Average correlations are now negative in the low volatility state and zero in the high volatility state. State transition

${ }^{12}$ While these numbers may seem low, it should be recalled that this is only because the global return factor (common to all stocks) has been taken out. 
probabilities for the industry returns listed in Table 5 at 0.87 and 0.96 are quite high and imply average duration of 27 months in regime 1 and 26 months in regime 2 . Consequently the steady state probabilities are 23 and 77 percent, so that three times as much time is spent by the industry portfolios in the low volatility regime (state 2 ).

While the extent to which industry return correlations vary across states is not uniform, it is interesting to note that the correlation between information technology (IT) returns and the other industry returns is large and negative $(-0.28)$ in the high volatility state. Since the smoothed state probability plots suggest that the common industry component has been in the high volatility state since 1998, it is clear that, during the recent IT boom and bust, the correlation between the IT and other industry returns was lower than during its low volatility state, where the correlation was -0.10 on average.

Figure 3 plots the time series of the smoothed probabilities for the high volatility state identified by the common country and common industry models as well as the model for global returns. The high persistence in the common country component stands out. For example, the common country effect stays in the same regime over the period 1986-1997, although it is difficult to interpret in terms of periods of high and low volatility. ${ }^{1} \mathrm{~m}$ contrast, the global return component follows shorter, cyclical movements that nevertheless are well separated by the model. This model thus identifies more regime shifts than the models fitted to the common country and industry portfolios. The common industry regime identifies four high volatility periods around the oil shock of the early seventies (1974), an episode in 198081, a spell from 1986 to September 1987 followed by the more recent period beginning in early 1998.

Although the series are clearly different, they still share some similarities. For a significant part of the period, the state probability for the common country factor is negatively correlated with that for the common industry factor, pointing to the alternating importance of these two factors in explaining overall stock return volatility over time. (The correlation between the smoothed state probabilities of the common industry and country return components is -0.27 ). The common country state variable has a correlation of -0.10 with the global state variable. Finally the industry and global state processes are strongly positively correlated with a sample correlation of 0.42 . This is to be expected, since many shocks to the global component are industry specific shocks, such as the oil shocks of the 1970s and the worldwide IT boom in recent years. We return to this point below.

These results clearly appeal to intuition. The finding that the global return component is the least persistent factor makes sense as it is likely to capture large, common economic shocks that may reflect variations in the global business cycle. In contrast, common country

${ }^{13}$ Interestingly, comparing the state plots in Figure 1 to the middle panel in Figure 3, the single country whose state probability series is most closely correlated with the common country state variable (at a correlation of 0.62 ) is the US. 
components are less likely to undergo frequent shifts as they are more based on structural relations. Themmon industry component lies somewhere in between in terms of its persistence.

\section{Variance Decompositions}

A key question addressed by the literature on country and industry effects is the relative size of these effects as measured by the relative volatility of geographically or industrially diversified portfolios. To get a first measure of how the total systematic variance evolves over time, we simply sum the global variance, the average country variance and the average industry variance (all based on conditional moment information reflecting the timevarying state probabilities) as follows:

$$
\begin{aligned}
\sigma_{t}^{2}= & \sum_{s_{\alpha t}} \pi_{s_{\alpha t}}\left(\sigma_{s_{\alpha t}}^{2}+\left(\mu_{\alpha s_{\alpha t}}-\bar{\mu}_{\alpha t}\right)^{2}\right) \\
& +\sum_{S_{\beta_{t}}} \pi_{s_{\beta t}}\left(\boldsymbol{\omega}_{\beta t}^{\prime} \boldsymbol{\Omega}_{\beta s_{\beta t}} \boldsymbol{\omega}_{\beta t}+\boldsymbol{\omega}_{\beta \mathbf{t}}^{\prime}\left(\boldsymbol{\mu}_{\beta s_{\beta t}}-\overline{\boldsymbol{\mu}}_{\beta t}\right)^{2}\right) \\
& +\sum_{S_{\gamma_{t}}} \pi_{s_{\gamma t}}\left(\boldsymbol{\omega}_{\gamma \mathrm{t}}^{\prime} \boldsymbol{\Omega}_{\gamma \mathrm{\gamma}_{\gamma t}} \boldsymbol{\omega}_{\gamma \mathrm{t}}+\boldsymbol{\omega}_{\gamma \mathbf{t}}^{\prime}\left(\boldsymbol{\mu}_{\gamma s_{\gamma t}}-\overline{\boldsymbol{\mu}}_{\gamma t}\right)^{2}\right),
\end{aligned}
$$

where $\boldsymbol{\omega}_{\beta t}$ is the vector of weights for the industry portfolios and $\boldsymbol{\omega}_{\gamma t}$ is the vector of weights of country porfolios. $\overline{\boldsymbol{\mu}}_{\alpha t}=\sum_{s_{\alpha t}} \pi_{s_{\alpha t}} \boldsymbol{\mu}_{\alpha s_{\alpha t}}$ is the conditional expectations of the global portfolio returns, $\overline{\boldsymbol{\mu}}_{\beta t}=\sum_{s_{\beta t}} \boldsymbol{\pi}_{s_{\beta t}} \boldsymbol{\mu}_{\beta s_{\beta t}}$ and $\overline{\boldsymbol{\mu}}_{\gamma t}=\sum_{s_{\gamma t}} \boldsymbol{\pi}_{s_{\gamma t}} \boldsymbol{\mu}_{\gamma_{\gamma_{t}}}$ are JX1 and Kx1 vectors of conditionally expected returns on the industry and country portfolios, respectively. The first component in (11) accounts for the total variance of the global return component. The second component is the value-weighted industry variance, while the third component is the value-weighted country variance. Besides accounting for state-dependent covariances, there is an extra component in each of these terms arising from variations in the means across states. Notice that this measure of total systematic variance changes over time due to timevariations in the state probabilities. 15

${ }^{14}$ See, e.g. , Solnik and Roulet (2000) "However, in periods of considerable economic shocks, when global factors strongly influence all economies, the general level of correlation between all markets increases. While the structural relations, which explain differences in correlation across market pairs, are likely to remain quite stable in the short run, this is not the case for the general level of correlation." (page 13)

15 The squared terms in the variance expression enter due to the binomial nature of the state variable, c.f. Timmermann (2000). 
Figure 4 plots the time-series of the systematic volatility component computed by taking the square root of (11). Systematic volatility varies considerably over time from a lowpoint around $2.8 \%$ to a peak around $5.5 \%$ per month. It was very high around 1974/75, 1980, 1987, 1991 and from late 1997 onwards. At these times, the systematic volatility component was close to twice as large as during the low volatility regimes that occurred in the late seventies and mid-nineties. Recalling that the volatility of the country component does not vary much across the two states, while conversely the volatility of the industry and global portfolio returns are about twice as high in the high volatility state as they are in the low volatility state, it is easy to understand the figure. Systematic volatility tends to be high when the common industry component and the global component are both in the high volatility state at the same time, i.e. in 1974, 1980, 1987 and from 1998 to 2002. Conversely, if they are simultaneously in the low volatility state, then systematic volatility will be low. Overall, our estimates also indicate that systematic volatility is trendless, a result consistent with Schwert's (1989) finding that market volatility has no significant long-term trend.

The measure of systematic variance in (11) neadily lends itself to a decomposition of the total systematic variance into its three constituents. Figure 5 shows the fraction of total systematic variance represented by the average country, average industry and global components scaled by the sum of these. Time variation in the (average) country fraction is very large and ranges from about two-thirds to one-third as in recent years. In particular, the importance of the country factor has been noticeable lower in periods of well-known global shocks such as the 1974-75 oil shock, the 1987 stock market crash and the information technology boom of the late 1990's. Such ups and downs in the relative contribution of the country factor do not lend much support to the notion sometimes popularized in the financial press that greater cross-border freedom in capital movements over the past decade or so has been gradually undermining the importance of country-specific shocks (see, e.g., Farrell, 2000), as changes in the country factor contribution have been anything but monotonic.

Likewise, the fraction of the total systematic volatility due to the industry component also varies considerably as shown in the middle panel of Figure 5. It rises to about thirty percent in the immediate aftermath of the two oil shocks of the 1970s (1974 and 1980/81), during the stock market crash of 1987, and during the IT boom and bust cycle from 1997/98 onwards. In the context of the existing literature, the estimated average level in the 10 to 15 percent range is slightly higher than the 7 percent figure of Heston and Rouwenhorst (1995) and more than twice as high as the estimates in Griffin and Karolyi's (1998) - both based on linear single-state models as discussed above. Figure 5 clearly unveils significant changes

${ }^{16}$ Griffin and Karolyi (1998) present two sets of estimates, one using a nine-sector breakdown and the other using 66 industry breakdown. They find that the mean industry factor contribution to total return variance are 2 and 4 percent respectively, a lot lower therefore than the above estimates. One possible reason for the lower estimate of Griffin and Karolyi (1998) relative to Heston and Rouwenhorst (1995) as well as ours is the inclusion of emerging markets in their sample. As country-specific shocks have been shown to play a 
in the relative importance of the industry factor and shows that its recent rise has in fact been the most persistent of all over the past thirty years, though not quite yet to the point where its relative to contribution to systemic volatility has surpassed that of the country factor as claimed by Cavaglia et al (2000). As shown in the bottom panel of Figure 5, this is partly due to the concomitant rise of the global factor contribution to overall stock return volatility in recent years which has filled some of the gap arising from the decline in country-specific volatility.

An alternative and complementary measure of the relative significance of the industry and country contributions to portfolio returns follows the decomposition scheme proposed in Griffins and Karolyi (1998) and replicated by others (e.g., Baca et al., 2000). The methodology proposed in this paper allows us to extend this framework by both letting the relative contributions of each factor vary across states and taking into account the various industry covariances within each state. As in Griffins and Karolyi (1998), let the excess return on the national stock market or portfolio of country $k$ (over and above the global portfolio return $\hat{\alpha}$ ) be decomposed into country $k$ 's unique industry weights times the industry returns summed across industries (i.e., $\sum_{j=1}^{J} \omega_{j k t}^{\beta} \hat{\beta}_{j t}$ ) plus a "pure" country effect $\hat{\gamma}_{k t} .17$

$$
R_{k t}-\hat{\alpha}_{t}=\sum_{j=1}^{J} \omega_{j k t}^{\beta} \hat{\beta}_{j t}+\hat{\gamma}_{k t}
$$

where $\omega_{j k t}^{\beta}$ is the $j t h$ industry's weight in country $k$. The variance of this excess return conditional on the country state being $s_{\gamma t}$ and the industry state being $s_{\beta t}$ is

$$
\operatorname{Var}\left(R_{k t}-\hat{\alpha}_{t} \mid s_{\beta t}, s_{\gamma t}\right)=\left(\boldsymbol{\omega}_{k t}^{\beta}\right)^{\prime} \mathbf{\Omega}_{\beta_{s \beta}} \boldsymbol{\omega}_{k t}^{\beta}+\mathbf{e}_{k}^{\prime} \mathbf{\Omega}_{\gamma_{\gamma}} \mathbf{e}_{k}+2\left(\boldsymbol{\omega}_{k t}^{\beta}\right)^{\prime} \operatorname{Cov}\left(\beta_{j t}, \gamma_{k t} \mid s_{\beta t}, s_{y t}\right),
$$

where $\boldsymbol{\omega}_{\mathrm{kt}}^{\beta}$ is the $J$-vector of market capitalization weights of the industries in country $k$.

greater role in the determination of stock returns in emerging markets (Serra, 2000), this is to be expected. However, we show below that much of the difference appears to be model and time dependent. Furthermore, Griffin and Karolyi consider a much shorter sample of weekly returns so differences in estimates are not all that surprising.

${ }^{17}$ It is straightforward to show that this decomposition follows from re-writing equation (2) for each individual country portfolio, where the individual firm's weight is the share of that firm in total market capitalization of the respective country portfolio. 
Similarly, the excess return on the portfolio of industry $j$ (over and above the global portfolio) can be decomposed into industry $j$ ' $s$ unique country weights times the country returns summed across countries plus a pure industry effect, $\hat{\beta}_{j t}$ :

$$
R_{j t}-\hat{\alpha}_{t}=\sum_{k=1}^{K} \omega_{j k t}^{\gamma} \hat{\gamma}_{k t}+\hat{\beta}_{j t}
$$

where $\omega_{j k t}^{\gamma}$ is the $k t h$ country's weight in industry $j$. The variance of this excess return conditional on the country state being $s_{\gamma t}$ and the industry state being $s_{\beta t}$ is

$$
\operatorname{Var}\left(R_{j t}-\hat{\alpha}_{t} \mid s_{\beta t}, s_{\gamma t}\right)=\left(\boldsymbol{\omega}_{j t}^{\gamma}\right)^{\prime} \mathbf{\Omega}_{\gamma_{s \gamma}} \boldsymbol{\omega}_{j t}^{\gamma}+\mathbf{e}_{j}^{\prime} \boldsymbol{\Omega}_{\beta s_{\beta}} \mathbf{e}_{j}\left(\boldsymbol{\omega}_{j t}^{\gamma}\right)^{\prime}+2 \operatorname{Cov}\left(\beta_{j t}, \gamma_{k t} \mid s_{\beta t}, s_{y t}\right),
$$

where $\boldsymbol{\omega}_{k t}^{\gamma}$ is the $\mathrm{K}$-vector of market capitalization weights of the countries in industry $j$.

Panel A in Table 7 reports the time-series variances of the "pure" country effects and the cumulative sum of the industry effects in the 13 country portfolios, while Panel B reports the time-series variances of the pure industry effects and the cummulative sum of country effects in the 11 industry portfolios. In both cases, these variances are expressed as a ratio relative to the total variances of the excess returns. Their sum is therefore close, but not exactly one due to the presence of the extra covariance term in (1 3 ) and (15) between the industry and country effects.

Since country volatility does not vary greatly over the two states, to save space Table 7 simply presents results separately for the high and low industry volatility state. While a number of individual country and sector results are of interest in their own right, looking at the overall means, two findings stand out. First, the 3.3 percent figure reported in the upper right panel is overall measure of the industry factor contribution in the low industry volatility state, which is well within the range previously estimated by Griffins and Karolyi (1998) (2 and 4 percent depending on the level of industry disaggretation - see tables 2 and 3 of their paper). Turning to the left panel, however, one can see that the same measure yields a much higher estimate of the aggregate industry component in the country portfolios (22.3 percent on average). In both the high and low industry volatility states, the average pure country volatility accounts for over $90 \%$ of the total country volatility - the fact that the right- and the left-hand side estimates in Panel A add to 120 percent being due to the higher negative

18 These measures are slightly different from those reported in Griffin and Karolyi (1998)in that they account for inter-industry covariances (in (13)) and inter-country covariances (in (15)). However, the results are not very sensitive to modifying our formulas so that they are instead based on sums of variances of individual industry or country effects. 
covariance between the pure country and the composite industry effect during the high industry volatility state.

Moving to the breakdown of the industry portfolios shown in the bottom panels of Table 7, it is clear that the aggregate contribution of country effects to industry portfolios is also state sensitive, being much lower (17 percent) in the high industry volatility state than in the low industry volatility state where it more than doubles (41 percent). Similarly, the pure industry contribution accounts for $91 \%$ of the total industry portfolio volatility in the high industry volatility state but only for $69 \%$ in the low industry volatility state. These results therefore suggest that decomposition results reported in the existing literature vary considerably over economic states.

\section{Implications for Global Portfolio Diversification}

The above decompositions of systematic variance are based on the average country and industry variances. As such they are statistical measures that do not represent the payoffs from a portfolio investment strategy since they ignore covariances between the returns on the underlying country, industry and global equity portfolios. The advantage of such measures is that they provide a clear idea of the relative size of the variances of returns on the three components (global, industry and country). Investors, however, will be interested in economic measures of volatility and risk that represent feasible investment strategies and hence account for covariances between returns on the different portfolios involved. Moreover, changes in these covariances have potentially very important macroeconomic implications. For instance, when such covariances increase, domestic risk becomes less diversifiable what in turn tends to raise the equity premia on a variety of portfolios and drive up the overall cost of capital for firms.

The large literature on the links between national stock markets finds that the covariance of (excess) returns between national stock indices displays considerable variation over time (King, Sentana, and Wadhwani, 1994; Lin, Engle, and Ito, 1994; Longin and Solnik, 1995; Karolyi and Stulz, 1996). In this section, we use firm level data and the methodology laid out in the previous sections to characterize the behavior of country portfolio covariances. Like King, Sentana, and Wadhwani (1994) we let such time variation in country covariances be driven by an unobserved latent variable but, unlike those authors, we characterize such variations in terms of relatively lenghty historical periods or "states" and allow for differences in industry composition across countries to play a role. Likewise, the same approach is used to characterize the covariance patterns of the various industry portfolios. The respective estimates are presented in sub-section 6.1. Using these estimates, variations in the volatility of investment strategies exposed to country- and industry risks are then examined in section 6.2. 


\subsection{Variations in covariances across states}

The joint models ((9) - (10)) assume separate state processes for the global return factor (which affects all stocks in every period) and for the country or industry returns. Each of these state variables can be in the high or low volatility state. The return on a geographically diversified portfolio invested in industry $j$ will be $\alpha_{\mathrm{t}}+\beta_{\mathrm{jt}}$, while the return on an industrially diversified country portfolio is $\alpha_{\mathrm{t}}+\gamma_{\mathrm{kt}}$. For such portfolios there are thus four possible state combinations. For example, for the industry portfolios the four states are

high industry volatility, high global volatility $\left(\mathrm{s}_{\beta \mathrm{t}}=1 ; \mathrm{s}_{\alpha \mathrm{t}}=1\right)$

high industry volatility, low global volatility $\left(\mathrm{s}_{\beta_{\mathrm{t}}}=1 ; \mathrm{s}_{\alpha \mathrm{t}}=2\right)$

low industry volatility, high global volatility $\left(\mathrm{s}_{\beta \mathrm{t}}=2 ; \mathrm{s}_{\alpha \mathrm{t}}=1\right)$

low industry volatility, low global volatility $\left(\mathrm{s}_{\beta \mathrm{t}}=2 ; \mathrm{s}_{\alpha \mathrm{t}}=2\right)$

The correlation between geographically diversified industry portfolios is likely to vary strongly according to the underlying combination of global and industry state variables. By construction, the global component is common to all stocks. Thus, when the global return variable is in the high volatility state, it will contribute relatively more to variations in the returns of such portfolios and correlations will increase. In contrast, when the global return component is in the low volatility state, correlations between country or industry portfolios will tend to be lower.

Similarly, when the industry component is in the low volatility state, the relative significance of the common global return component is larger so that correlations between industry portfolios will be stronger compared to when the industry return process is in the high volatility state. Given the very large differences between volatilities in the high and low volatility states observed for the global and industry portfolios, these effects are likely to give rise to large differences between correlations of geographically diversified industry portfolios in the four possible states.

A complication arises when computing these correlations as they are depend on the correlation between the global and industry or country portfolio returns. Terms such as $\operatorname{Cov}\left(\alpha_{t}, \gamma_{k t} \mid s_{t}, s_{\gamma t}\right)$ can be consistently estimated as follows:

$$
\begin{aligned}
& \operatorname{Cov}\left(\alpha_{t}, \beta_{j t} \mid s_{\alpha t}, s_{\beta t}\right)=\frac{\sum_{t=1}^{T} \pi_{s_{\alpha t}} \pi_{s \beta t}\left(\alpha_{t}-\hat{\alpha}_{s_{\alpha t}}\right)\left(\beta_{j t}-\hat{\beta}_{j s_{\beta t}}\right)}{\sum_{t=1}^{T} \pi_{s_{\alpha t}} \pi_{s_{\beta t}}} \\
& \operatorname{Cov}\left(\alpha_{t}, \gamma_{k t} \mid s_{\alpha t}, s_{\gamma t}\right)=\frac{\sum_{t=1}^{T} \pi_{s_{\alpha t}} \pi_{s \gamma k}\left(\alpha_{t}-\hat{\alpha}_{s_{\alpha t}}\right)\left(\gamma_{k t}-\hat{\gamma}_{k s_{\gamma t}}\right)}{\sum_{t=1}^{T} \pi_{s_{\alpha t}} \pi_{s \gamma t}} \\
& \operatorname{Cov}\left(\beta_{t}, \gamma_{t} \mid s_{\beta t}, s_{\gamma t}\right)=\frac{\sum_{t=1}^{T} \pi_{s_{\beta t}} \pi_{s_{\gamma t}}\left(\beta_{j t}-\hat{\beta}_{j s_{\beta t}}\right)\left(\gamma_{k t}-\hat{\gamma}_{k s_{\gamma t}}\right)}{\sum_{t=1}^{T} \pi_{s_{\beta t}} \pi_{s \gamma t}}
\end{aligned}
$$


To investigate just how different these correlations and volatilities are, Table 8 presents the estimated covariances and correlations in the four possible states for the industrially diversified country portfolios, while Table 9 presents the estimated covariances and correlations for the geographically diversified industry portfolios. Variances are presented on the diagonals, covariances above the diagonal and correlations below the diagonal.

For the country portfolios, some interesting findings emerge. First, correlations across countries vary substantially, even after allowing for cross-country differences in industry composition. In particular, correlations are generally higher among the Anglo-Saxon countries (notably between Canada, US, and the UK) and lowest between the US and much of continental Europe and Japan. This result is consistent with the evidence of other studies using different methodologies andmeasures (see, e.g., IMF, 2000) and our estimates show that it broadly holds across states. Second, correlations change markedly across states. Since there is not much difference between the variance of country returns in the high and low volatility states, the main driver of the results will be whether the global portfolio is in the high or low volatility state. The average correlation between the country portfolios is 0.30 in the low global volatility state and 0.56 in the high global volatility state. Thus, the state process for the global return component clearly makes a big difference to the average correlations between the country portfolios, almost doubling in the high volatility state.

Turning to the geographically diversified industry portfolios listed in Table 9, a richer picture emerges since the global high and low volatility states are now supplemented by the high and low industry volatility states. When the industry process is in the high volatility state while the global process is in the low volatility state, the average correlation across industry portfolios is only 0.19 . This rises to 0.50 when the industry and global processes are both in the high volatility state or both are in the low volatility state. Finally, when the industry state process is in the low volatility state while the global process is in the high volatility state, the average correlation across the geographically diversified industry portfolios is $0.81 .^{2}$ These results show that the average correlations between geographically diversified industry portfolios vary substantially according to the state process driving the common industry component and the global component, with the non-neglible differences in industry factor correlations within each state being especially magnified in the high industry volatility state. Finally we note how different the average volatility level is in the high and

${ }^{19}$ Among continental European countries, a main exception is the Netherlands whose country factor volatility is highly correlated with those of the US and the UK. Much of it, however, appears to reflect the behavior of one very large company (Shell) and the relative thinness of the Dutch country portfolio.

${ }^{20}$ Consistent with other findings in the literature, correlations between the industry portfolios are generally higher than the correlations between the country portfolios. 
low volatility states. For the country portfolios the variation in volatility is, unsurprisingly, somewhat smaller. The mean volatility is $6.4 \%$ per month in the high global volatility state and $5.3 \%$ in the low volatility state. The mean volatility of the industry portfolios is $6.6 \%$ per month in the high industry-, high global volatility state as compared with an average volatility of these portfolios of $3.6 \%$ in the low industry-, low global volatility state.

Significant economic consequences follow from these results. Generally, it will be much more difficult to diversify internationally or across industries when the global volatility process is in the high volatility state while the industry (country) process is in the low volatility state. This suggests that it is beneficial for investors to carefully keep track of the underlying state probabilities, particularly since the high persistence in the state probabilities implies considerable predictability of future states if the current state is reasonably precisely estimated.

\subsection{Volatility of portfolios exposed to country or industry risks}

An alternative economic measure of the country, industry and global factors' contribution to portfolio variance can be derived by considering a simple portfolio investment strategy that tilts the industry or country weights in proportion with their market capitalization. To set up such a portfolio, we define $\omega_{\beta t}$ as market capitalization weights for the industries and $\omega_{\gamma \mathrm{t}}$ as market capitalization weights for the countries. These are defined using beginning-of-month weights. Naturally, the weights sum to one in any given month, i.e., $\omega_{\beta t}^{\prime} l=\omega_{\gamma t}^{\prime} l=1$.

The conditional variance of a portfolio tilted towards industries in proportion with their market capitalization weights can be expressed as

$$
\sum_{s_{\beta t}} \pi_{s_{\beta t}}\left\{\omega_{\beta t}^{\prime} \boldsymbol{\Omega}_{\beta s_{\beta t}} \boldsymbol{\omega}_{\beta t}+\left(\boldsymbol{\omega}_{\beta t}^{\prime} \boldsymbol{\mu}_{\beta s_{\beta t}}-\overline{\bar{\mu}}_{\beta t}\right)^{2}\right\},
$$

where $\overline{\bar{\mu}}_{\beta t}=\sum_{s_{\beta t}} \pi_{s_{\beta t}}\left(\omega_{\beta t}^{\prime} \mu_{\beta s_{\beta t}}\right)$ is the expected industry portfolio return averaged across states and across industries.

Similarly, the conditional variance of a portfolio tilted towards countries in proportion with their market capitalization weights is

$$
\sum_{s_{\gamma t}} \pi_{s_{\gamma t}}\left\{\omega_{\gamma t}^{\prime} \boldsymbol{\Omega}_{\gamma s_{\gamma t}} \boldsymbol{\omega}_{\gamma t}+\left(\boldsymbol{\omega}_{\gamma t}^{\prime} \boldsymbol{\mu}_{\gamma s_{\gamma t}}-\overline{\bar{\mu}}_{\gamma t}\right)^{2}\right\},
$$

where $\overline{\bar{\mu}}_{\gamma t}=\sum_{s_{\gamma t}} \pi_{s_{\gamma t}}\left(\omega_{\gamma t}^{\prime} \boldsymbol{\mu}_{\gamma_{\gamma_{t}}}\right)$ is the expected country portfolio return averaged across states and across countries. 
Figure 6 reports the time-series of these measures of risk. Clearly the industry tilts give rise to a much higher volatility when the industry state variable is in the high volatility state, i.e. around 1974, 1980, 1987 and again from 1998 onwards. At these points in time the volatility of the tilted industry portfolios is between $1 \%$ and $1.4 \%$ per month, whereas its typical level is much lower around $0.20 \%$ per month. For the tilted country portfolio, the normal volatility is around 0.60 , but this rises to a higher level between $1 \%$ and $1.4 \%$ per month in 1978, 1981 and again in 1988. As expected, periods with high country volatility do not match up closely with the country states shown in Figure 3 since differences in volatility between these are not as pronounced as those found for the industry portfolios, c.f. Table 4.

Overall, these results demonstrate considerable time variation in the volatility associated with portfolios that are exposed either to country or to industry risks. As such they confirm the economic importance of accounting for regimes in common country- and industry factors.

\section{Conclusion}

This paper presented a novel two-stage methodology to measuring the relative contribution of global, and country and industry specific factors to stock return volatility. In the first stage, the Heston and Rouwenhorst $(1994,1995)$ dummy factor model of decomposing stock returns into global, industry, and country specific factors is used to create "pure" industry and "pure" country portfolios based on individual stock return data. Returns on these portfolios are then modeled individually or jointly as regime switching processes in the second stage. We estimate the model using a global firm level dataset spanning over three decades which is more suitable to capture the time-varying nature of stock return dynamics than the much shorter firm level datasets commonly employed in this literature. The results show that the proposed methodology not only fits the data better - with standard tests of model selection clearly rejecting the linear single regime specification commonly used in the literature - but also yield several key findings on the nature of stock return volatility.

First, for most countries and industries there is very strong evidence of two regimes characterized by very different levels of volatility. Both regimes tend to be highly persistent, with high volatility states proving to be the least persistent. This inverse relationship between volatility and persistence across states is clearly expected and consistent with the findings of previous work e.g. Ang and Bekaert (2002) and Perez-Quiros and Timmermann (2000). On average, individual country estimates show that high volatility states have a duration of about 16 months as opposed to 39 months for the low volatility state, whereas the respective estimates for individual industry estimates are 22 and 48 months.

Second, there is evidence of a significant common dynamic component in the vector of country and industry portfolio returns. The common country component is shown to be by far the most persistent, possibly reflecting slowly evolving country factors related to institutional changes, whereas the lower persistence of the common industry component 
appears to reflect a variety of global shocks that affect industries very differently, such as oil since the early 1970s and information technology more recently. Consistent with this hypothesis, the common industry volatility is very different across states, being more than twice as high in the high volatility state. Given these distinctive features of each state, the model is able to identify the timing of the various states for global, common country, and common industry components over the past thirty years showing, in particular, that the post1997 period has been unique in the juxtaposition of a relatively long-lasting high industry and high global volatility state.

Third, in allowing for non-linear dynamics and providing evidence of two distinct states, our model yields arguably more precise estimates of the time-series variation in the contribution of country and industry factors to stock return variance than earlier studies. Our estimates indicate that global and industry factors have increased in significance relative to the country factors since the late 1990s and that, in the recent state, the industry factor accounts for about one-third of total systematic (or non-idiosyncratic) variance in stock returns. Over the whole sample 1973-2002, we also show that the industry contribution has averaged some 10 percent - a figure that justifies earlier studies' emphasis on the importance of country vs. industry diversification strategies.

Last but not least, the paper shows that these results have important implications for global risk diversification and portfolio management strategies and that the methodology proposed is especially suitable to analyze the interaction between the dynamics of global, country, and industry factors over time. As discussed above, with the estimation of two states per factor, eight possible combinations arise and the correlations among country portfolios are shown to be strongest in the high global volatility state, and weakest in the low global volatility state. So, it is not surprising that in the high global volatility state such as that observed over approximately the past five years opportunities for global risk diversification have been lower but more significantly so across countries than across sectors. Timevariations in the relative volatility and correlations of country, industry and global factors clearly suggest that an optimal investment strategy should attempt to account for persistent regimes in these components. 


\section{References}

Ang, A. and G. Bekaert, 2001, "International Asset Allocation with Regime Shifts." Forthcoming in Review of Financial Studies.

Ang, A. and G. Bekaert, 2002, "Regime Switches in Interest Rates." Journal of Business and Economic Statistics, 20, 163 - 182.

Baca, S.P., B. Garbe, and R.A. Weiss, 2000, "The Rise of Industry Effects in Major Equity Markets," Financial Analysts Journal, September/October, pp. 35-40.

Beckers, S., G Connor, and R. Curds, 1996, "National versus Global Influences on Equity Returns.” Financial Analysts Journal, March/April, pp. 31-39.

Beckers, S., R. Grinold, A. Rudd, and D. Stefek, 1992, "The Relative Importance of Common Factors Across the European Equity Markets," Journal of Banking and Finance, Vol. 16, pp. 75-95.

Brooks, Robin and Luis Catão, 2000, “The New Economy and Global Stock Returns", IMF working paper WP/00/216.

Cavaglia, S., C. Brightman, and M. Aked, 2000, “The Increasing Importance of Industry Factors", Financial Analysts Journal, September/October, pp. 41-54.

David, A. and P. Veronesi, 2001, “Option Prices with Uncertain Fundamentals: Theory and Evidence on the Dynamics of Implied Volatilities and Over-/Underreaction in the Options Market”. Mimeo, Federal Reserve Borard of Governors and University of Chicago.

Davies, R., 1977, "Hypothesis Testing when a Nuisance Parameter Is Present Only Under the Alternative". Biometrica, 64, 247-254.

Driffill, J. and M. Sola, 1994, "Testing the Term Structure of Interest Rates from a Stationary Switching Regime VAR”. Journal of Economic Dynamics and Control 18, 601-628.

Farrell, C., 2000, “The New Global Investor: New Rules and New Tools for a Global Strategy," Business Week, September 11.

Gray, S., 1996, "Modeling the Conditional Distribution of Interest Rates as RegimeSwitching Process". Journal of Financial Economics 42, 27-62. 
Griffins, J. and G. Karolyi, 1998, "Another look at the role of industrial structure of markets for international diversification strategies," Journal of Financial Economics 50, pp. 351-373

Guidolin, M. and A. Timmermann, 2002, "Strategic Asset Allocation under Multivariate Markov Switching”. Mimeo, University of Virginia and UCSD.

Hamilton, J. 1988, "Rational Expectations Econometric Analysis of Changes in Regime: An Investigation of the Term Structure of Interest Rates". Journal of Economic Dynamics and Control 12, 365-423.

Hamilton, J., 1989, “A New Approach to the Economic Analysis of Nonstationary Time Series and the Business Cycle," Econometrica 57, 357-384.

Harvey, Campbell R. and Zhou, Guofu, 1993, "International Asset Pricing with Alternative Distributional Specifications”, Journal of Empirical Finance, Vol1, no.1, pp.107-131.

Heston, S. L. and K.G Rouwenhorst, 1994, "Does Industrial Structure Explain the Benefits of International Diversification," Journal of Financial Economics 36, pp. 3-27.

Heston, S. L. and K.G. Rouwenhorst, 1995, "Industry and Country Effects in International Stock Returns," The Journal of Portfolio Management, Spring, pp. 53-58.

IMF, 2000, "World Economic Outlook-Asset Prices and the Business Cycle," Washington D.C.: International Monetary Fund.

Karolyi, Andrew and René Stultz, 1996, "Why do Markets Move Together? An Investigation of U.S.-Japan Stock Return Comovements”, Journal of Finance 51(3), pp.951-86.

King, Mervin, Enrique Sentana, and Sushil Wadhwani, 1994, "Volatility and Links Between National Stock Markets, Econometrica 62, pp.901-33.

Lin, W.L., R.F. Engle, and T.Ito, 1994, "Do Bull and Bears Move Across Broders? Transmission of International Stock Returns and Volatility," Review of Financial Studies 7, pp.507-538.

Lo, A.K. and C. MacKinlay, 1988, "Stock Prices do not Follow Random Walks: Evidence from a Simple Specification Test," Review of Financial Studies 1, pp.41-66.

Longin, F. and B. Solnik, 1995, "Is the Correlation in International Equity Returns Constant: 1970-1990”, Journal of International Money and Finance 14, pp.3-26.

Longin, F. and B. Solnik, 2001, Extreme correlation of international equity markets," Journal of Finance, 56, 649-676. 
Pagan, A. and G.W. Schwert, 1990, “Alternative Models for Conditional Stock Volatility, Journal of Econometrics, 92, pp.307-328.

Perez-Quiros, G. and A. Timmermann, 2000, "Firm Size and Cyclical Variations in Stock Returns," Journal of Finance, 1229-1262.

Roll, R., 1992, "Industrial Structure and the Comparative Behavior of International Stock Market Indices," The Journal of Finance XLVII, pp. 3-42.

Rouwenhorst, K.G., 1999, "European Equity Markets and EMU: Are the Differences Between Countries Slowly Disappearing?”, Financial Analysts Journal, May-June, pp. 57-64.

Schwert, William, G., 1989, "Why Does Stock Market Volatility Change Over Time?", Journal of Finance 44, pp., 1115-1153

Serra, A. P., 2000, "Country and Industry Factors in Returns: Evidence from Emerging Markets' Stocks,” Emerging Markets Review, Vol.1, no.2.

Solnik, Bruno and Jacques Roulet, 2000, "Dispersion as Cross-Sectional Correlation," Financial Analysts Journal, vol. 56, no 1, pp. 54-61.

Timmermann, A., 2000, "Moments of Markov Switching Models", Journal of Econometrics $96,75-111$.

Turner, C. R. Startz, and C. Nelson, 1989, "A Markov Model of Heteroskedasticity, Risk and Learning in the Stock Market", Journal of Financial Economics 25, 3-22.

Whitelaw, R.F., 2001, “Stock Market Risk and Return: An Equilibrium Approach.” Review of Financial Studies 13, 521-548. 
Figure 1.A. Smoothed State Probabilities for Individual Countries (High Volatility State)
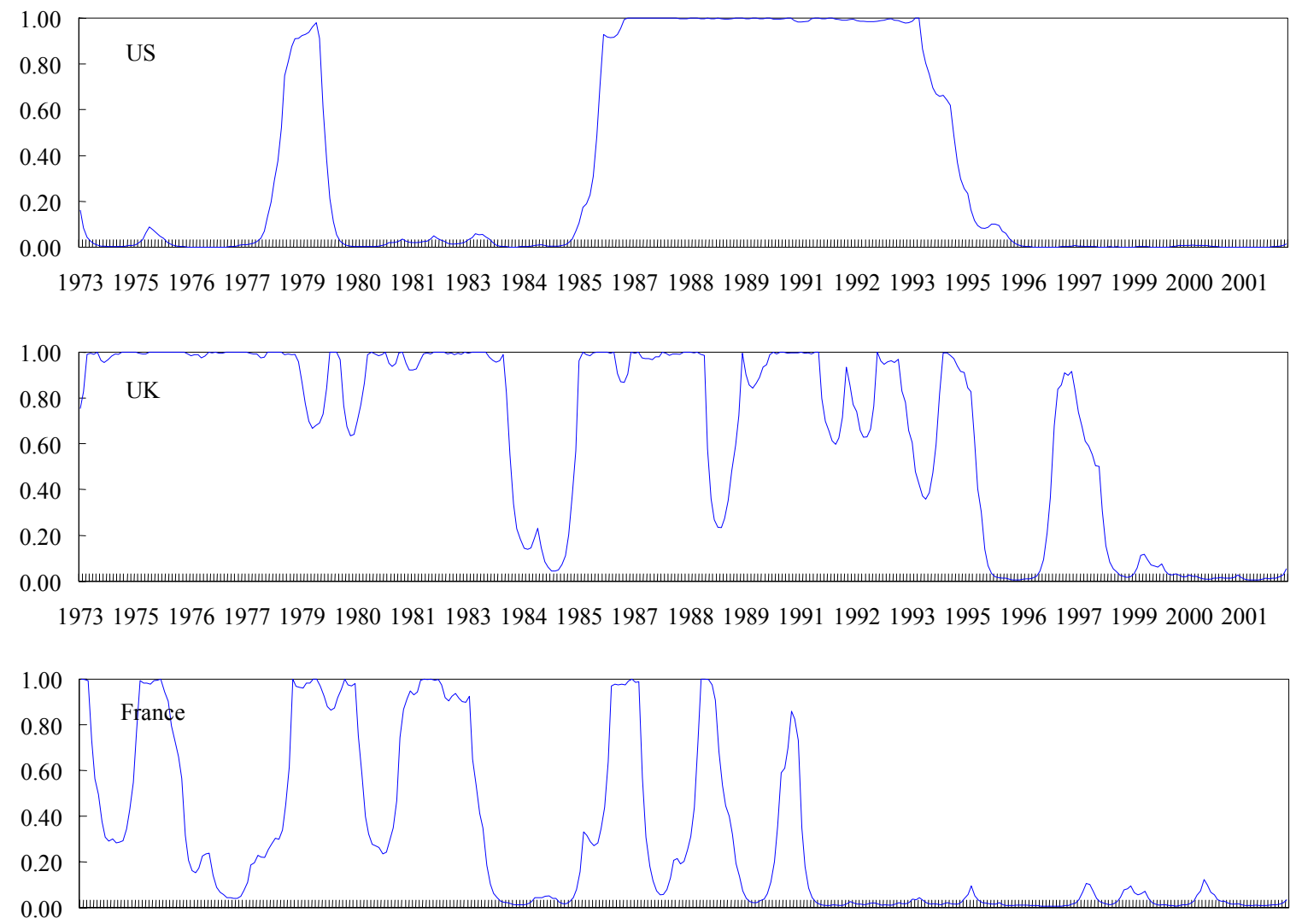

1973197519761977197919801981198319841985198719881989199119921993199519961997199920002001

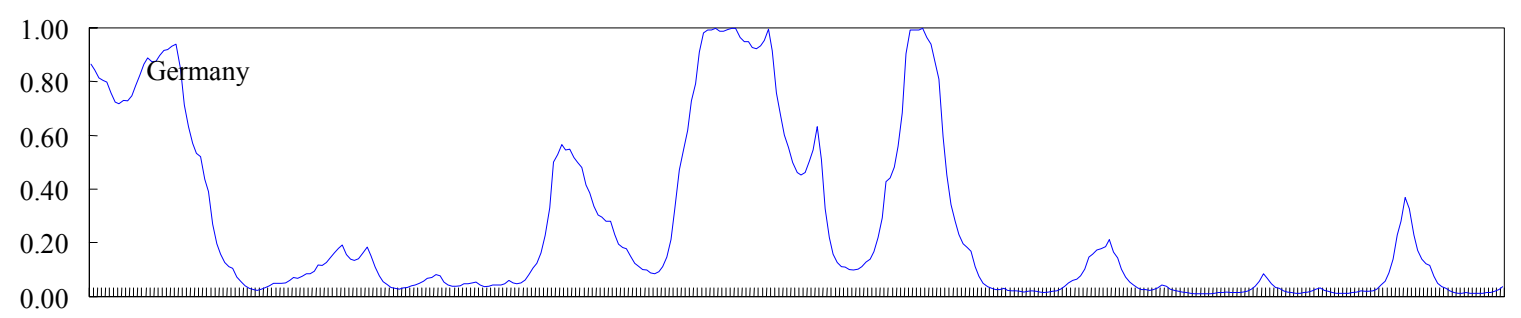

1973197519761977197919801981198319841985198719881989199119921993199519961997199920002001

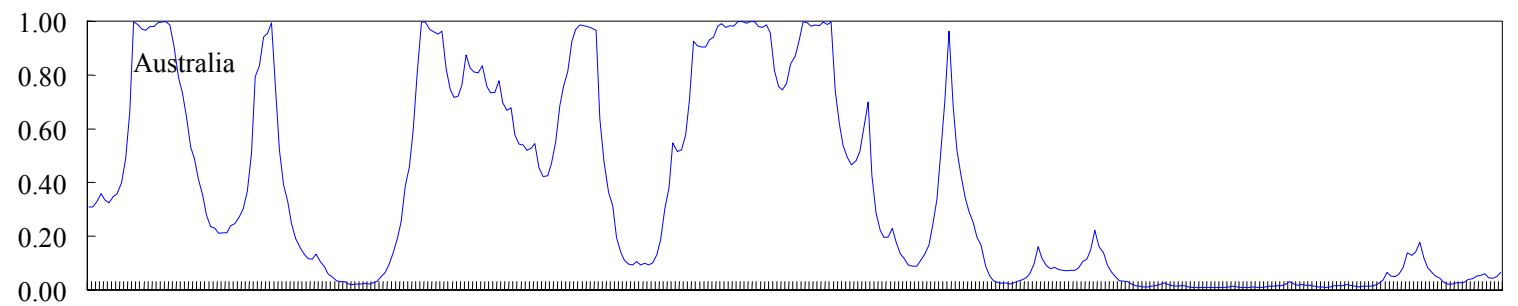

1973197519761977197919801981198319841985198719881989199119921993199519961997199920002001 
Figure 1.B. Smoothed State Probabilities for Individual Countries (High Volatility State)

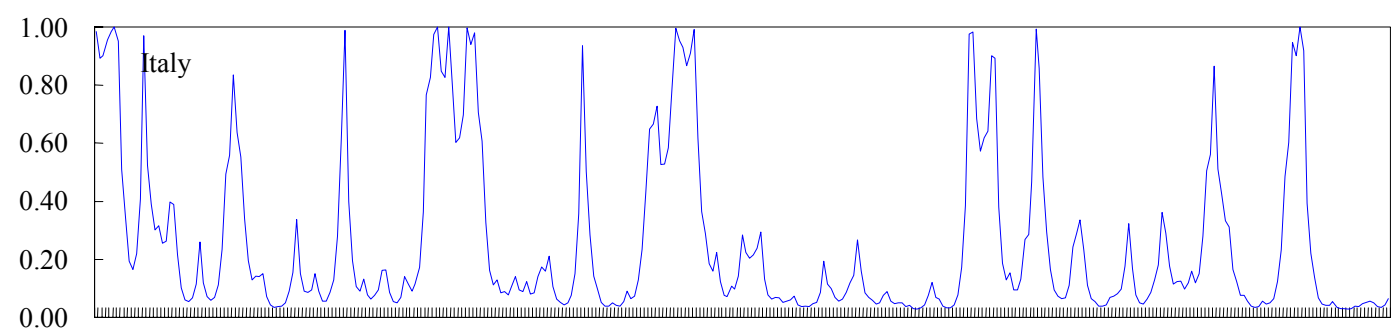

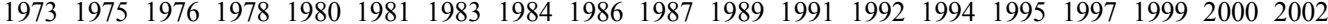

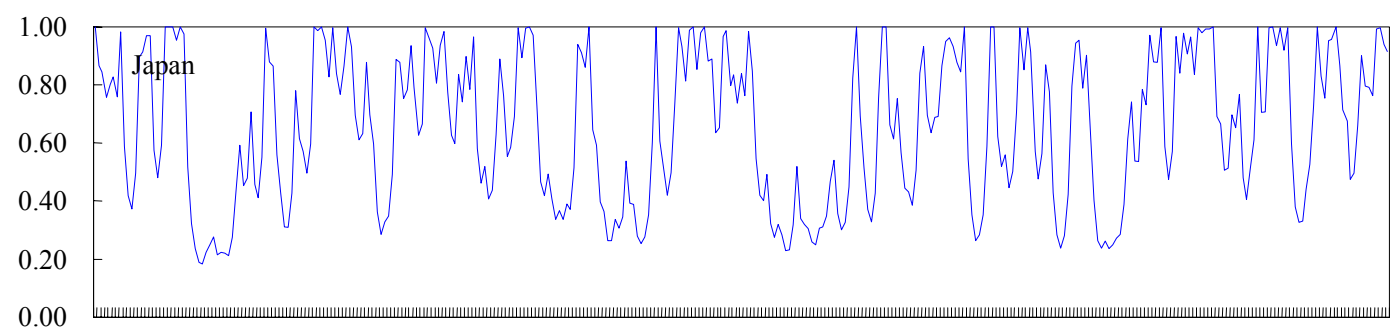

$\begin{array}{llllllllllllllllllll}1973 & 1975 & 1976 & 1978 & 1980 & 1981 & 1983 & 1984 & 1986 & 1987 & 1989 & 1991 & 1992 & 1994 & 1995 & 1997 & 1999 & 2000 & 2002\end{array}$

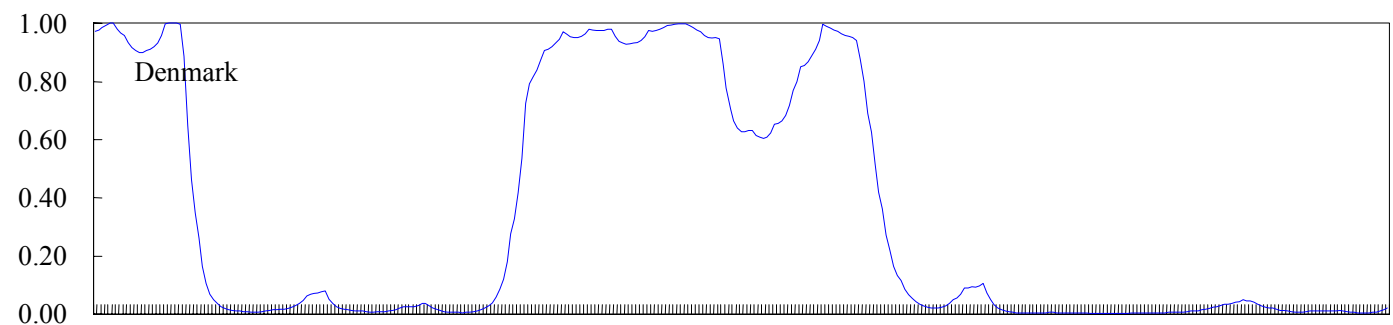

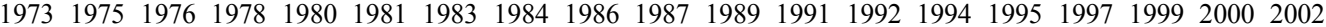

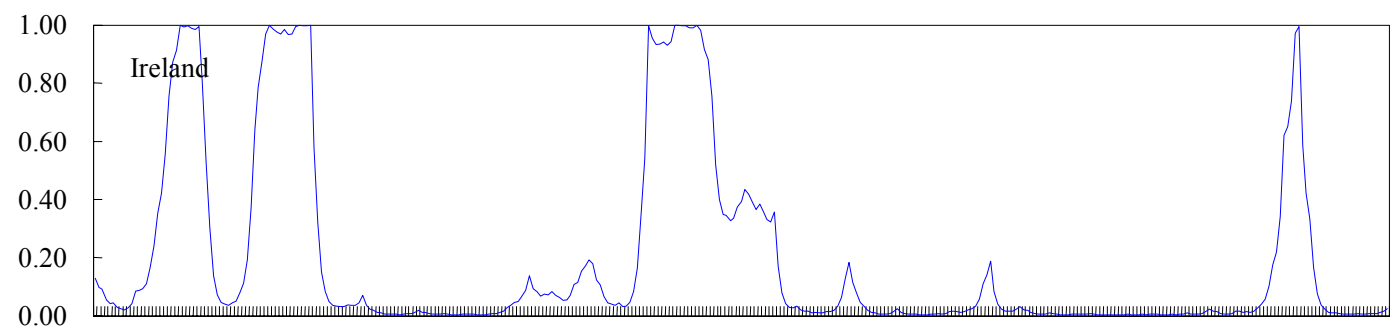

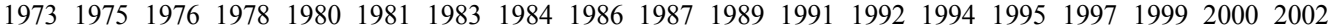

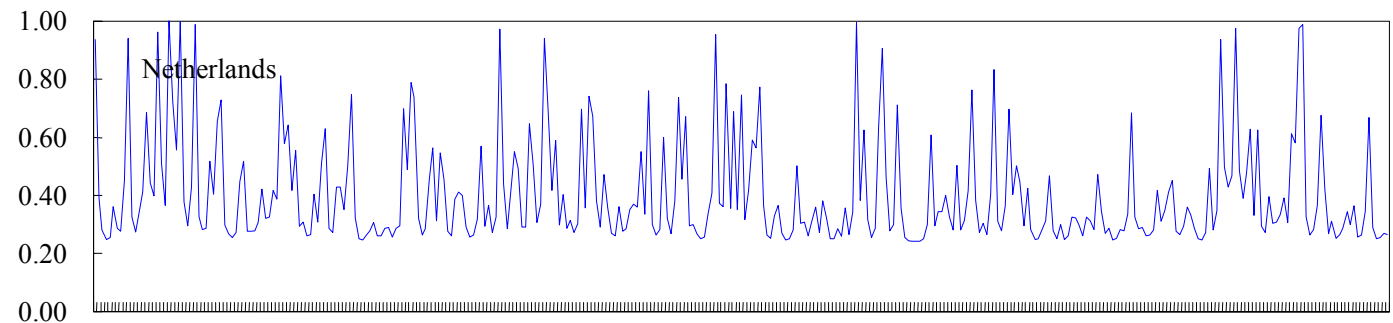

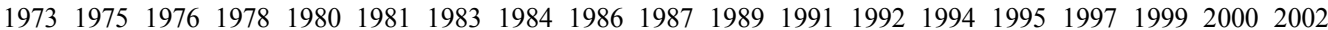


Figure 2.A. Smoothed State Probabilities for Individual Industries (High Volatility State)

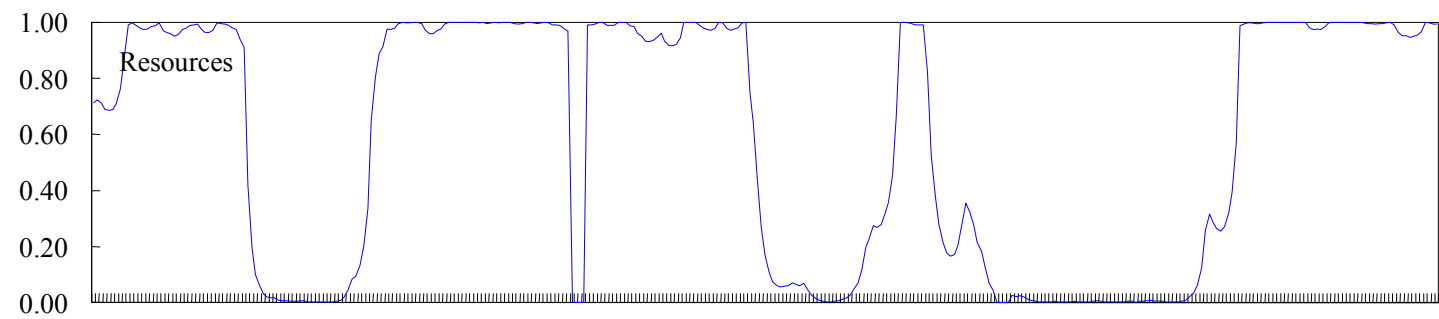

197319751976197719791980198219831985198619871989199019921993199419961997199920002002

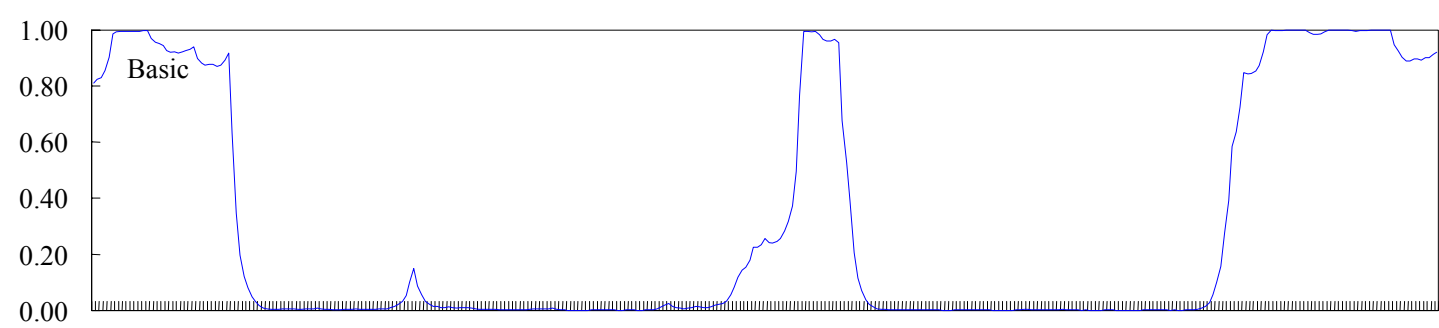

197319751976197719791980198219831985198619871989199019921993199419961997199920002002

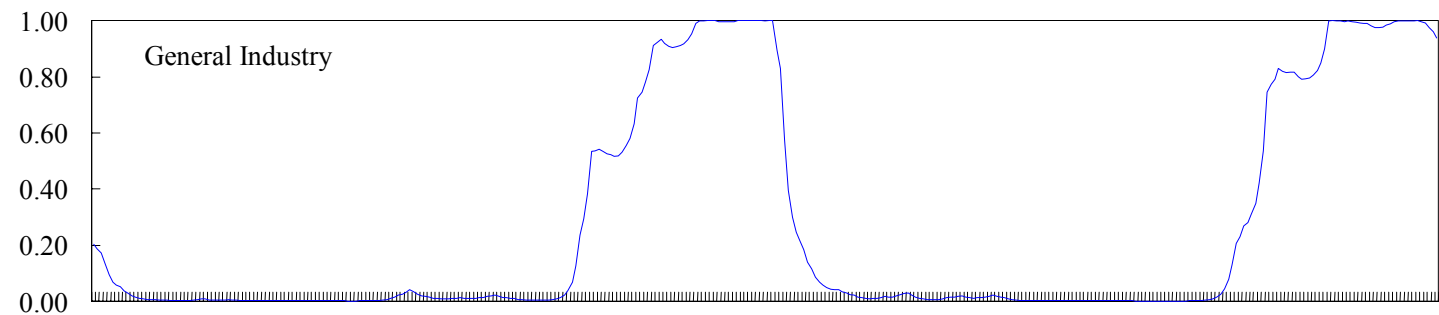

197319751976197719791980198219831985198619871989199019921993199419961997199920002002

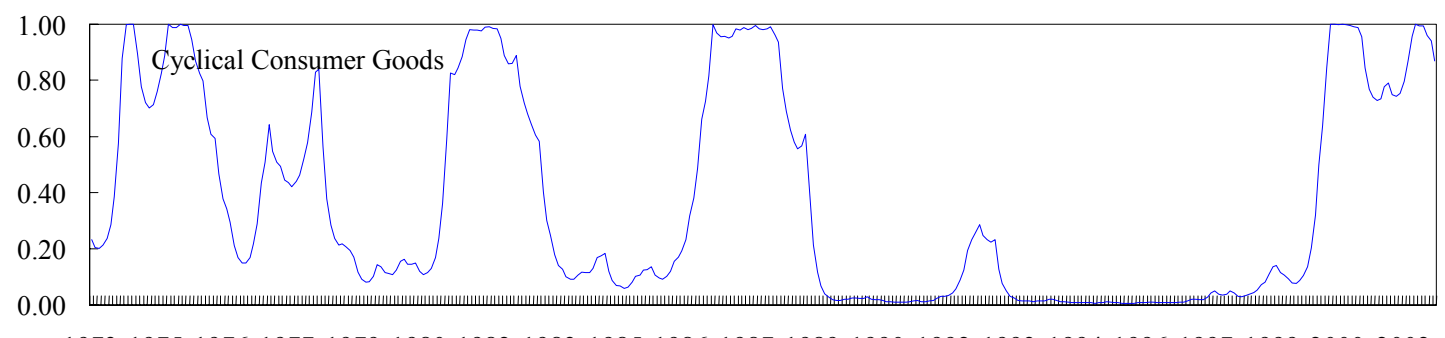

197319751976197719791980198219831985198619871989199019921993199419961997199920002002

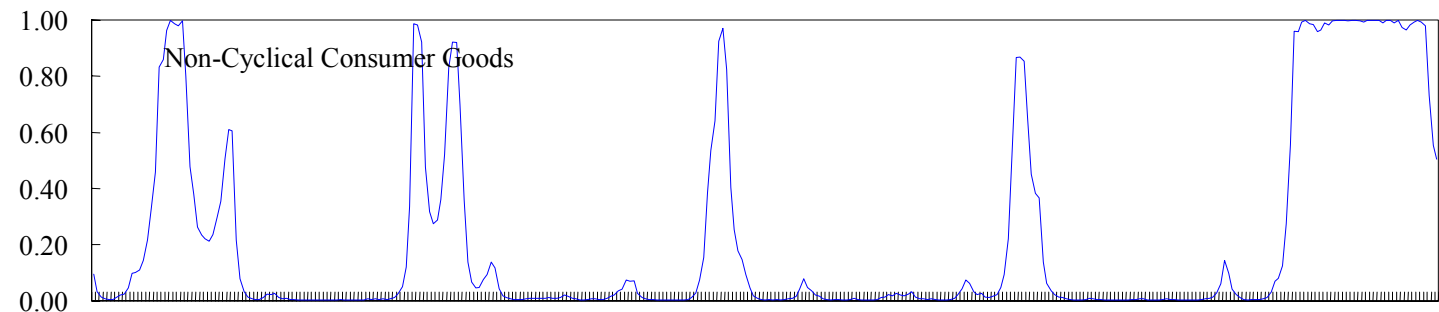

197319751976197719791980198219831985198619871989199019921993199419961997199920002002 
Figure 2.B. Smoothed State Probabilities for Individual Industries (High Volatility State)

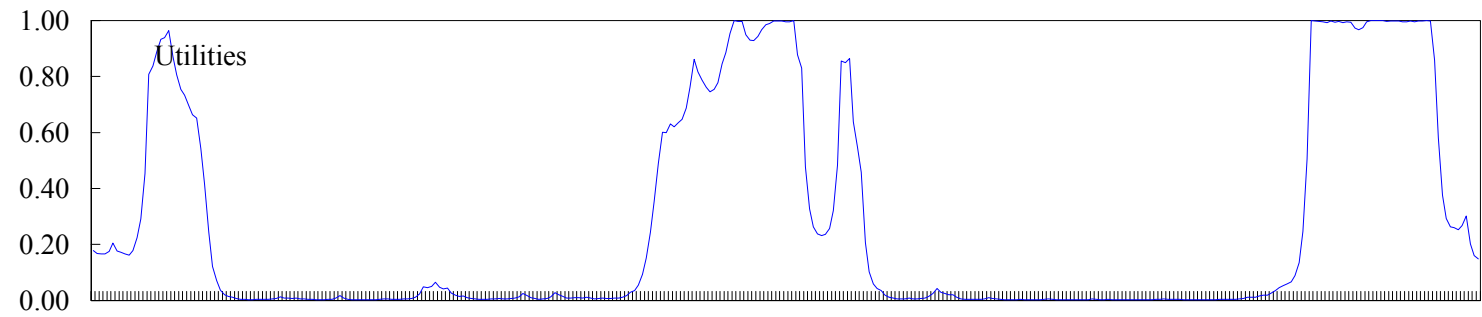

197319751976197719791980198219831985198619871989199019921993199419961997199920002002

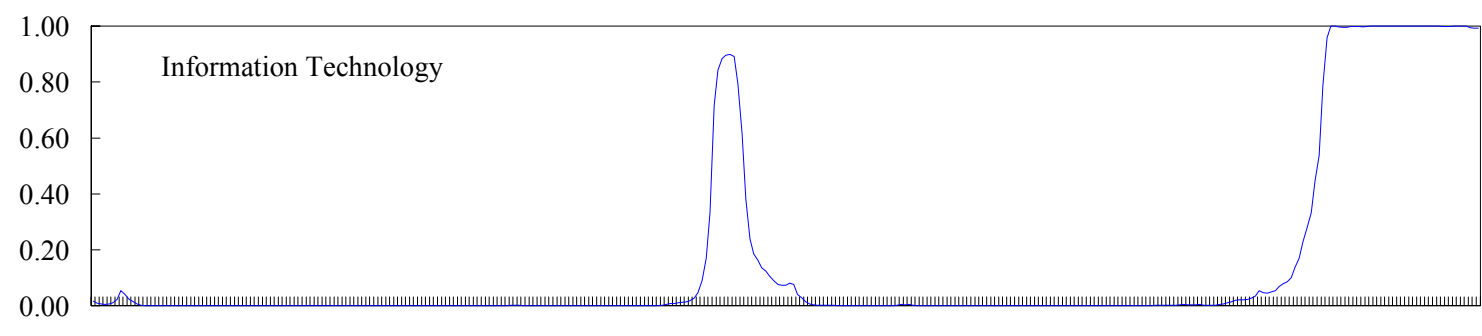

197319751976197719791980198219831985198619871989199019921993199419961997199920002002

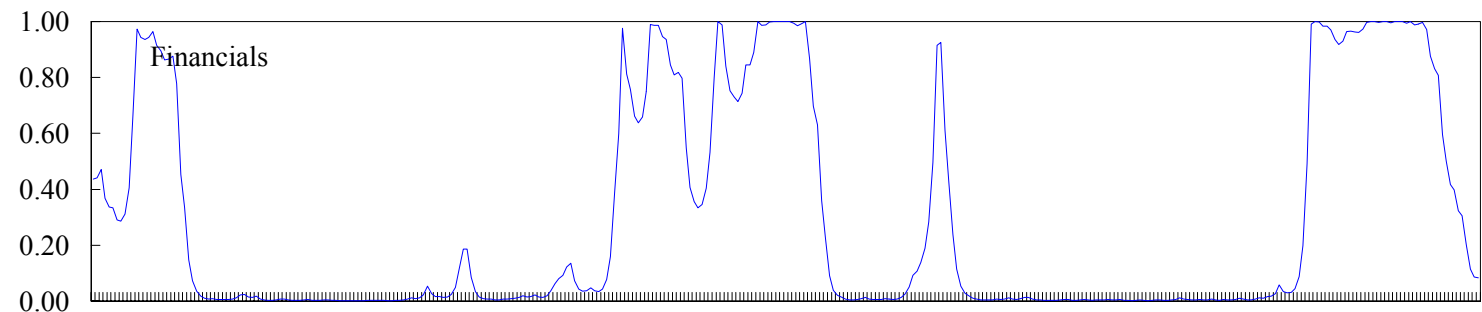

197319751976197719791980198219831985198619871989199019921993199419961997199920002002

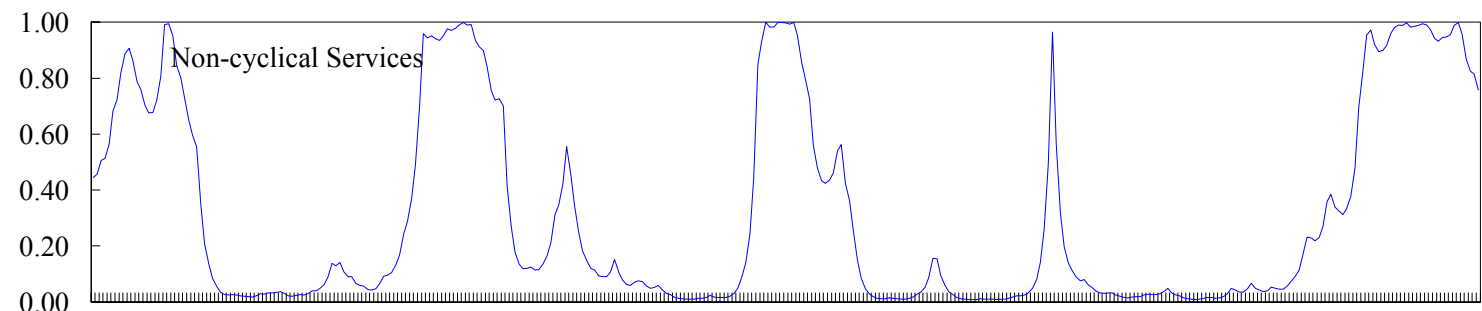

197319751976197719791980198219831985198619871989199019921993199419961997199920002002

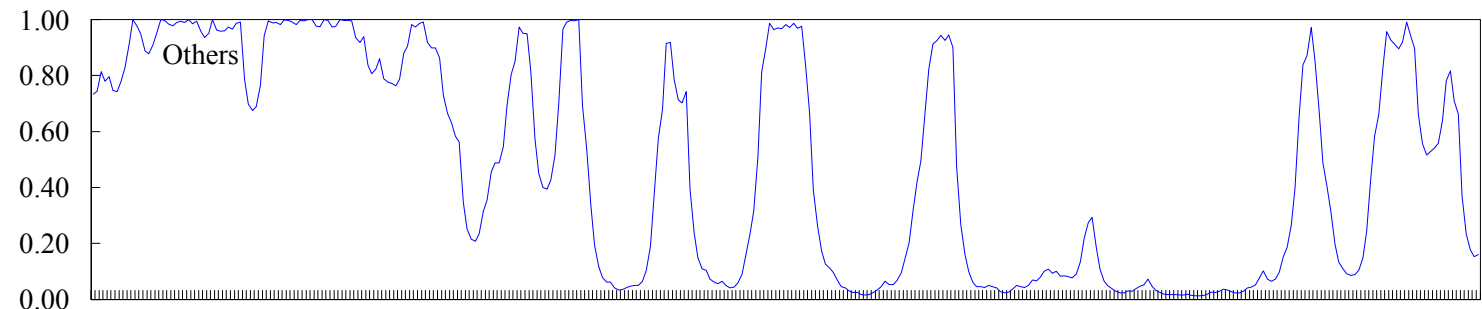

197319751976197719791980198219831985198619871989199019921993199419961997199920002002 
Figure 3. Smoothed State Probabilities for Common Components (High Volatility State)

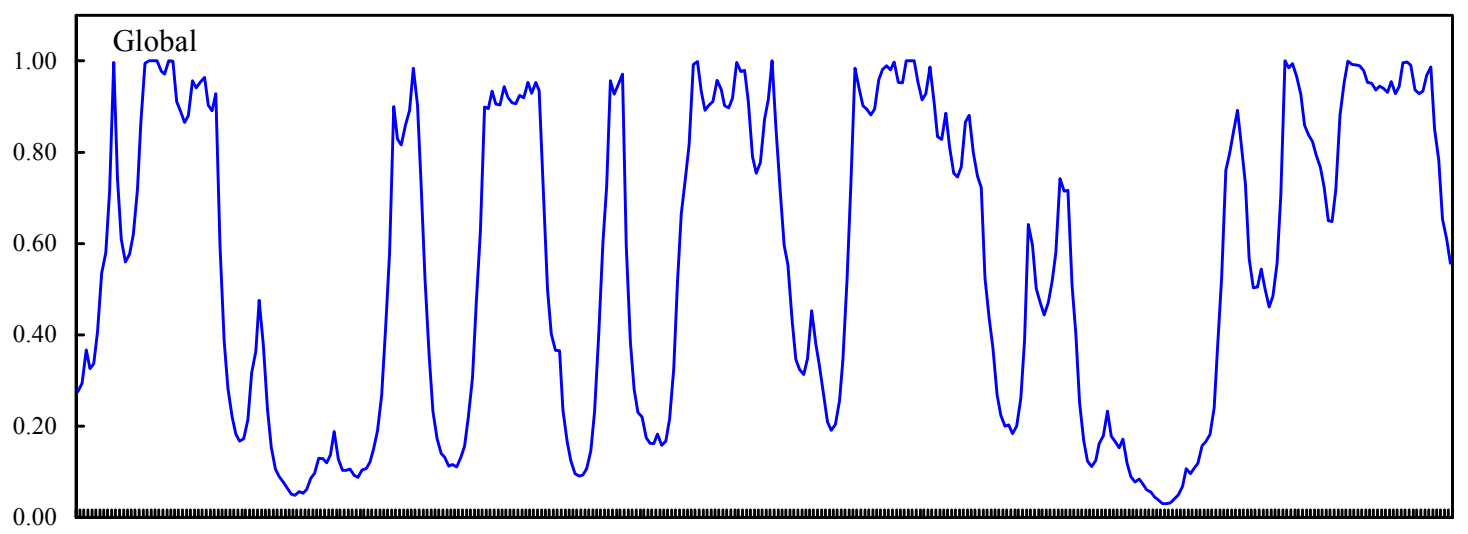

197319741976197719781979198119821983198419861987198819891991199219931994199619971998199920012002

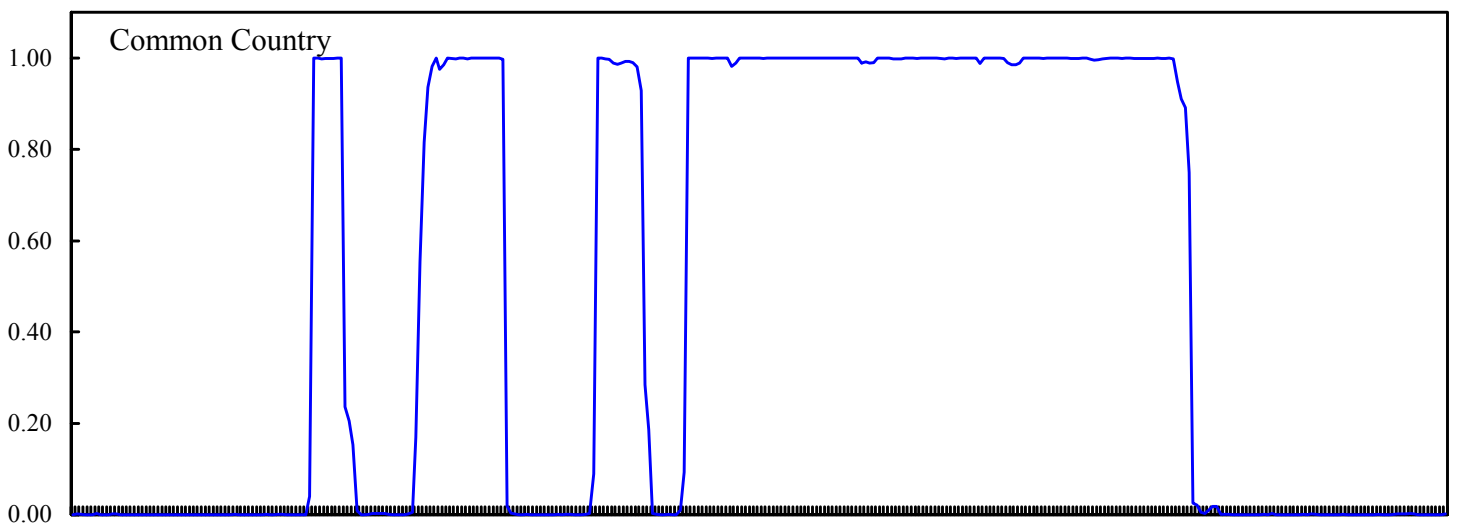

197319741976197719781979198119821983198419861987198819891991199219931994199619971998199920012002

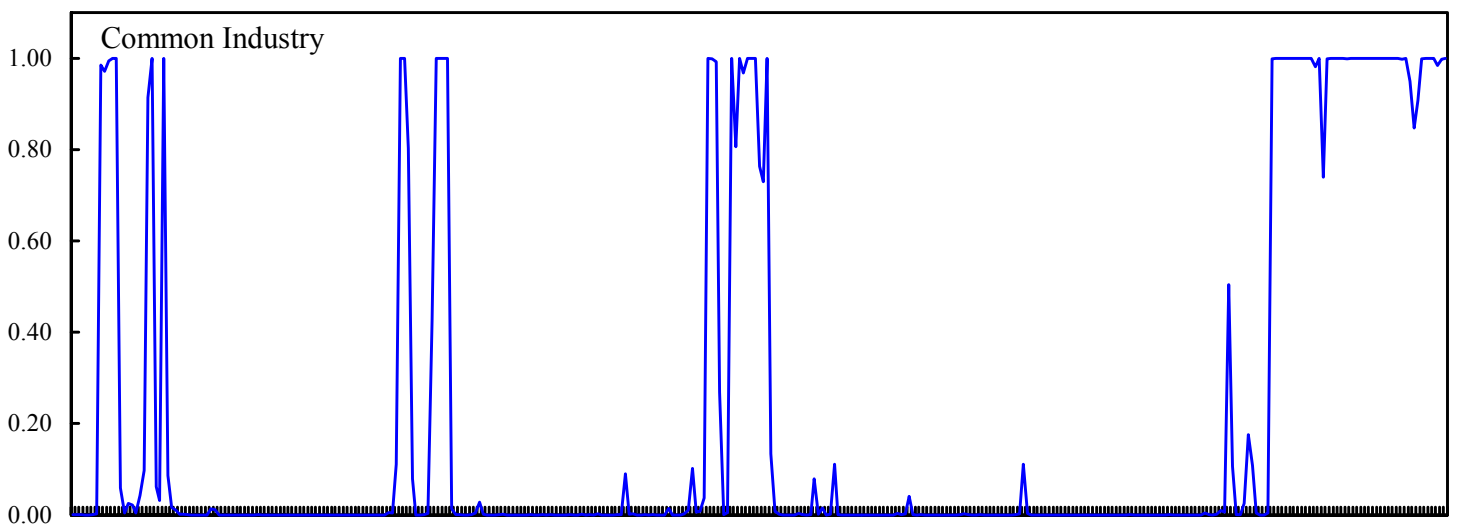

197319741976197719781979198119821983198419861987198819891991199219931994199619971998199920012002 


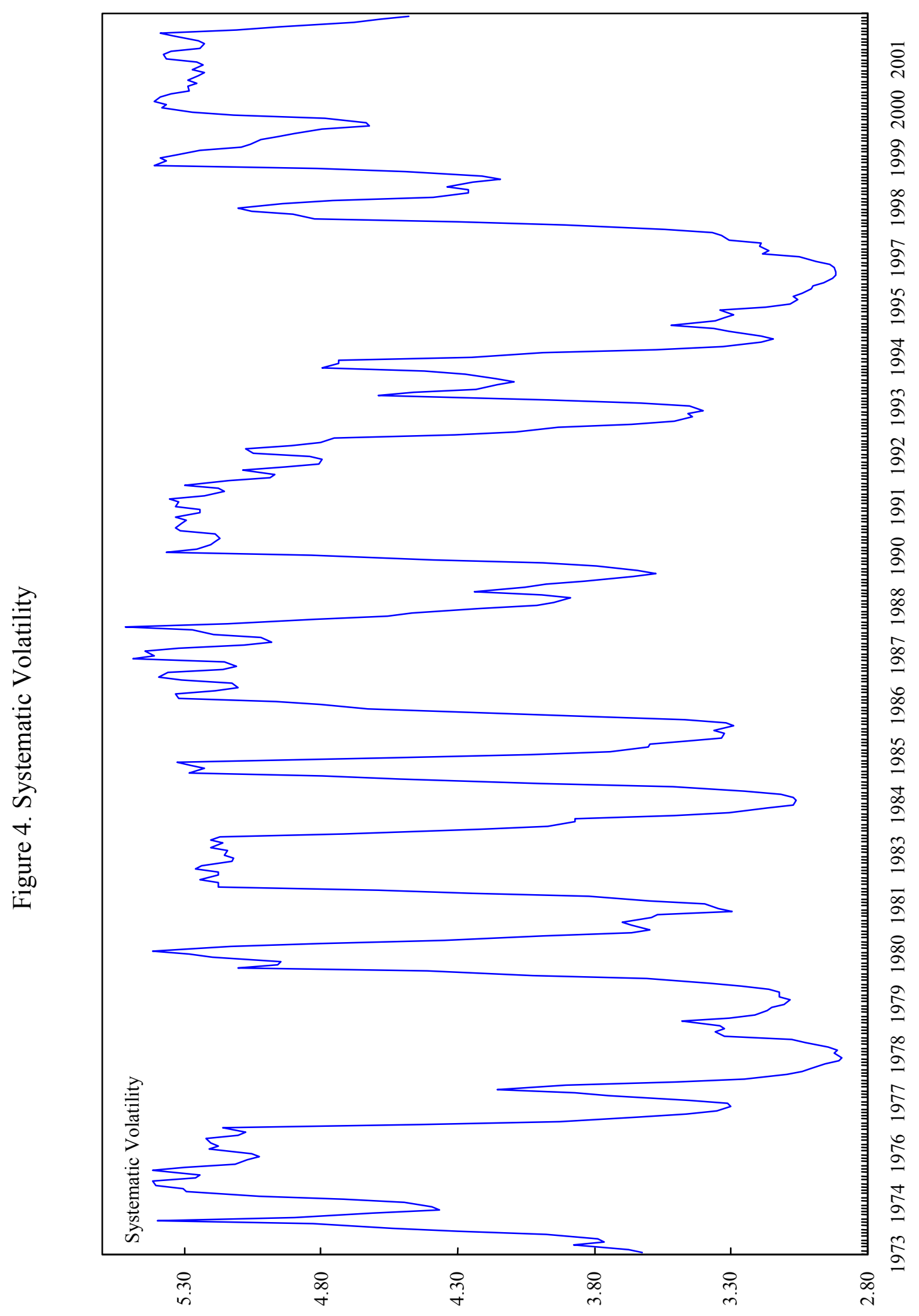


Figure 5. Decomposition of Systematic Variance into Country, Industry and Global Components

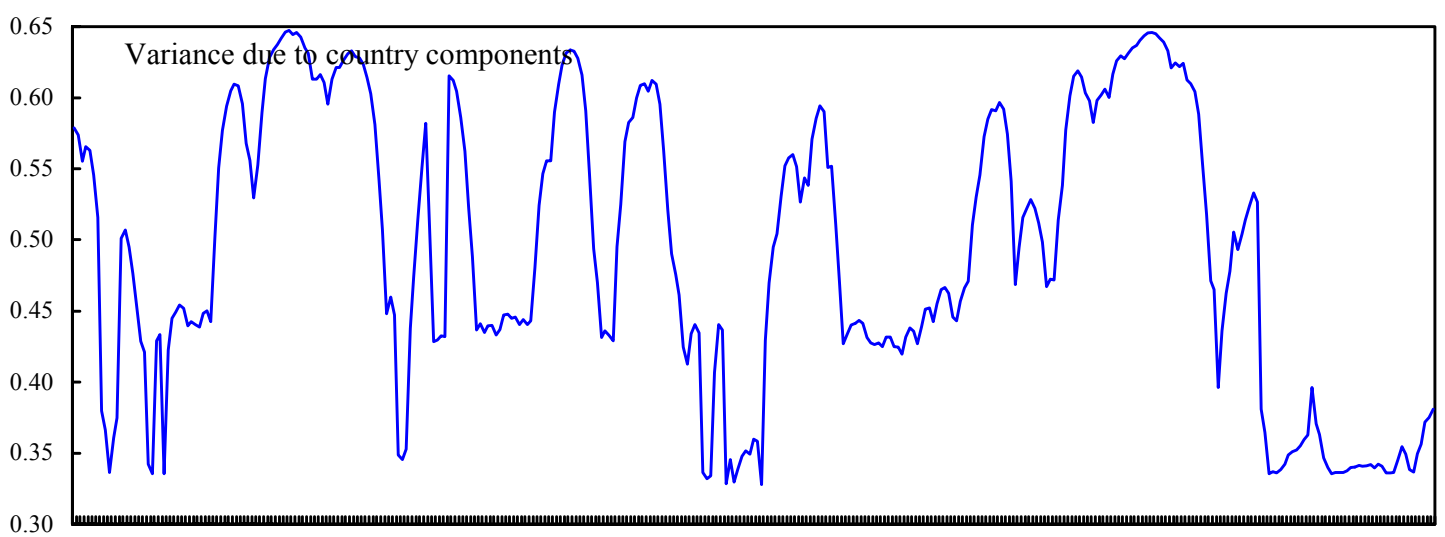

197319741976197719781979198119821983198419861987198819891991199219931994199619971998199920012002

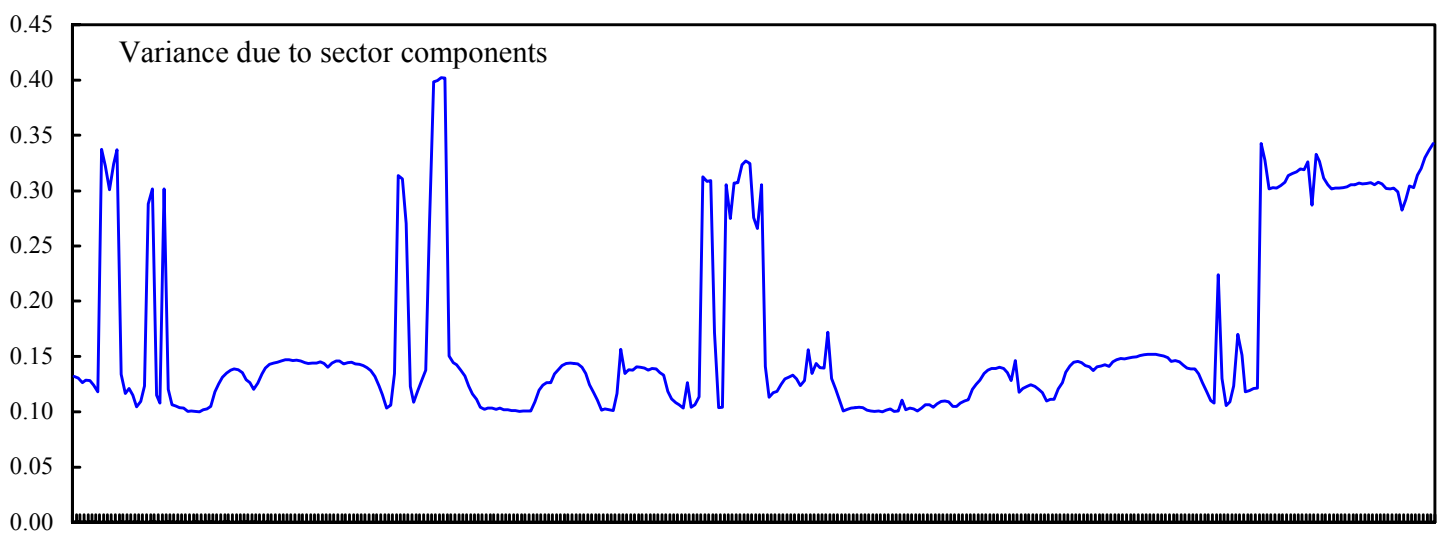

197319741976197719781979198119821983198419861987198819891991199219931994199619971998199920012002

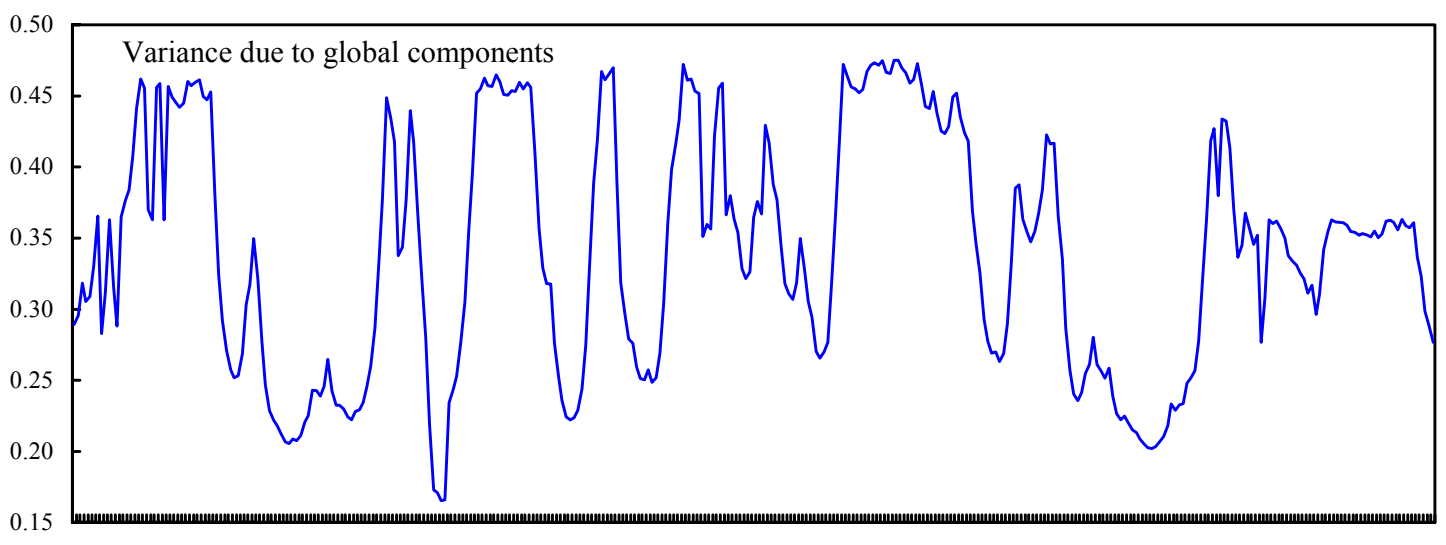

197319741976197719781979198119821983198419861987198819891991199219931994199619971998199920012002 
Figure 6. Volatility from Shifting Industry or Country Weights

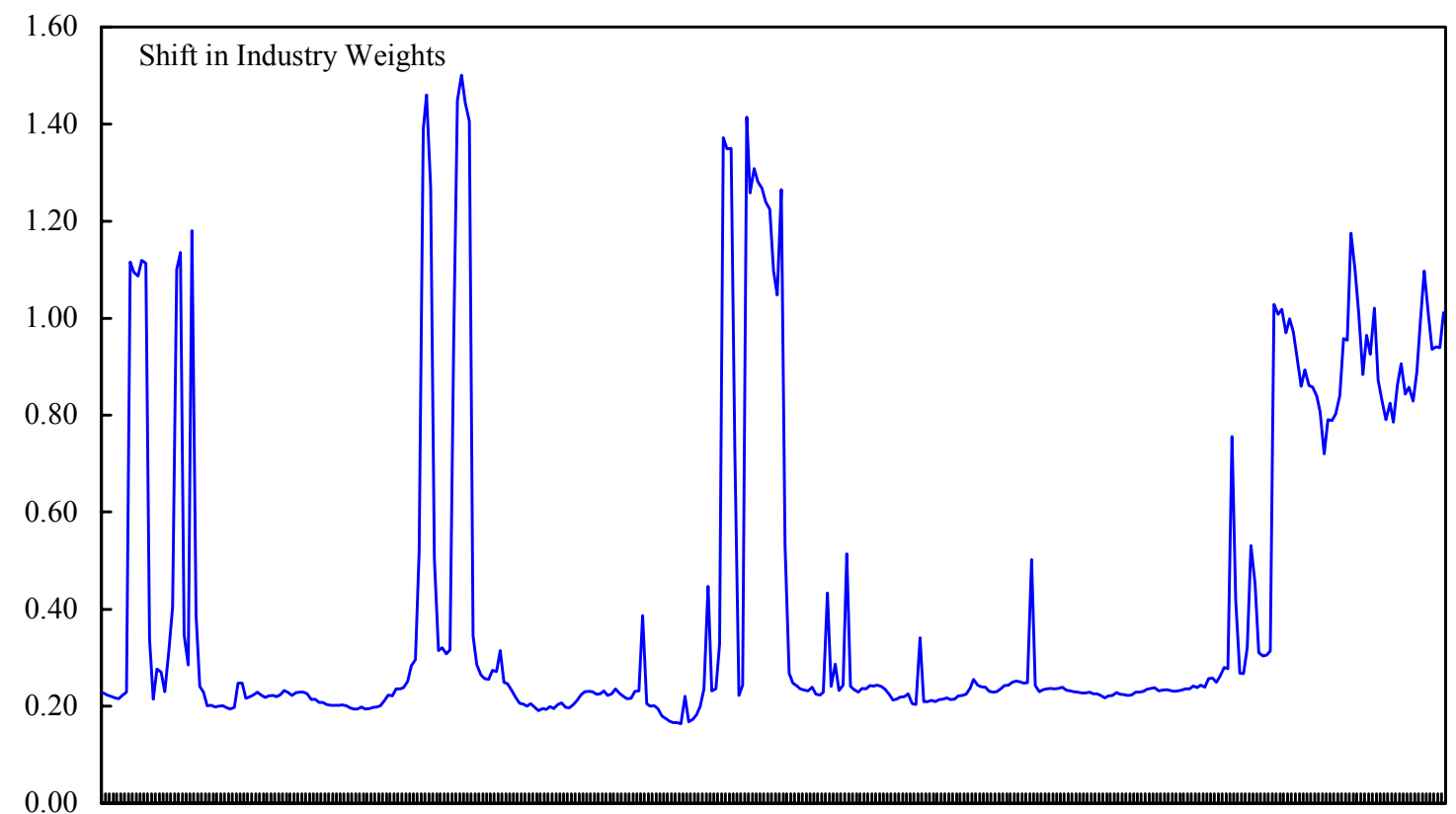

1973197519761978198019811983198419861987198919911992199419951997199920002002

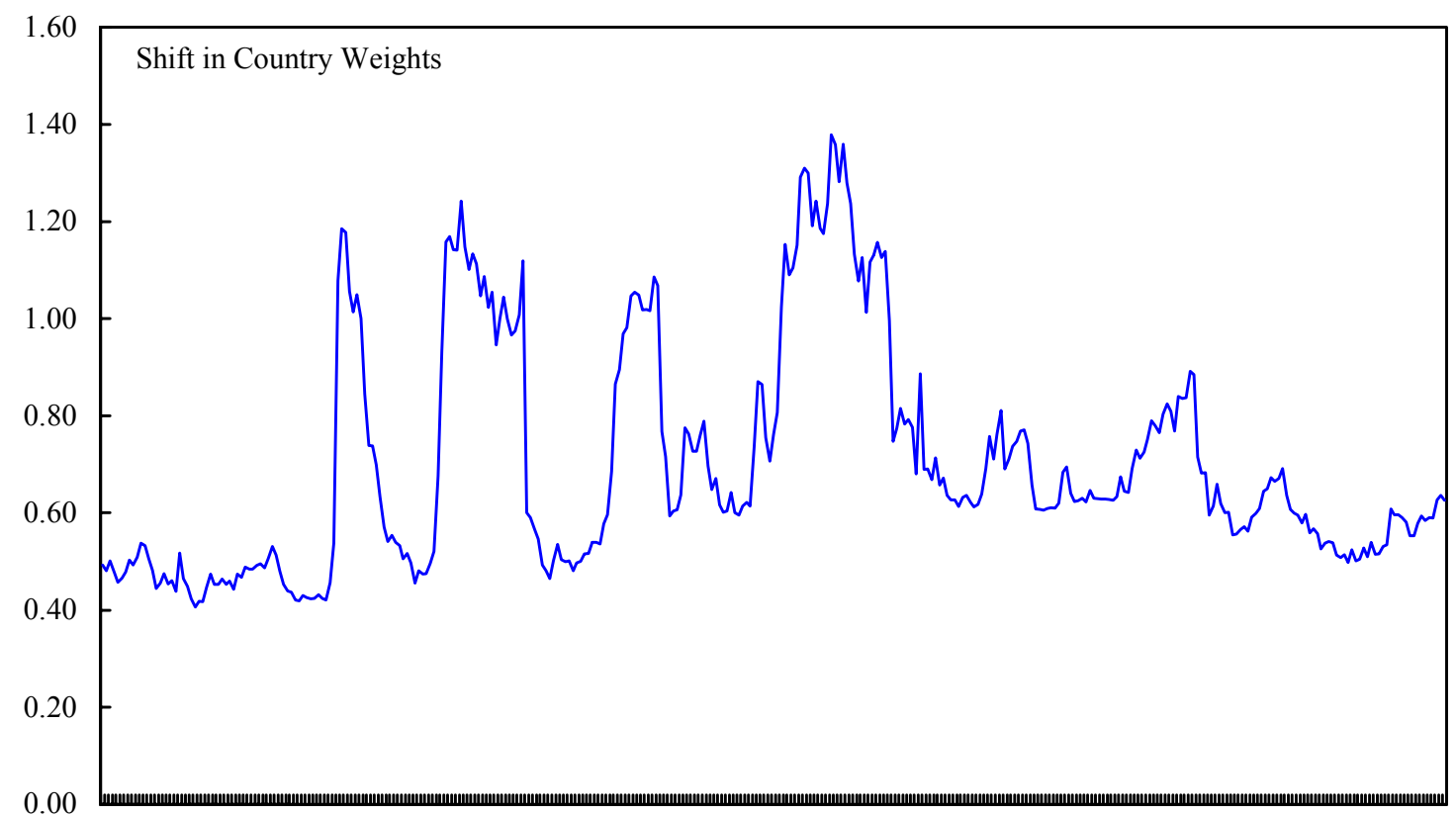

1973197519761978198019811983198419861987198919911992199419951997199920002002 
Table 1: Summary Statistics for the Country, Sector, and World Portfolio Return:

\begin{tabular}{lrrrr} 
& mean & s.d. & skew & kurtosis \\
\cline { 1 - 3 } A. Country portfolios & & & & \\
US & -0.12 & 2.77 & -0.42 & 2.48 \\
UK & 0.07 & 5.07 & 1.81 & 14.8 \\
France & 0.10 & 5.25 & 0.27 & 1.32 \\
Germany & -0.29 & 5.02 & -0.09 & 0.81 \\
Italy & -0.12 & 7.28 & 0.38 & 1.71 \\
Japan & 0.11 & 4.63 & 0.02 & 0.58 \\
Canada & -0.29 & 3.85 & -0.34 & 0.55 \\
Australia & -0.15 & 6.27 & -0.25 & 1.67 \\
Belgium & -0.22 & 4.65 & 0.60 & 1.87 \\
Denmark & -0.10 & 5.32 & 0.33 & 1.33 \\
Ireland & 0.18 & 6.11 & 0.55 & 2.72 \\
Netherlands & -0.12 & 3.31 & -0.04 & 1.02 \\
Switzerland & -0.28 & 4.04 & -0.02 & 0.09 \\
Average & -0.09 & 4.89 & 0.22 & 2.38 \\
& & & & \\
B. Industry portfolios & & & & \\
Resources & & & & \\
Basic & -0.12 & 3.74 & 0.03 & 0.88 \\
General industry & -0.19 & 2.52 & 0.06 & 3.71 \\
Cyclical durables & -0.05 & 1.78 & -0.40 & 1.24 \\
Non-cycl. durables & -0.09 & 3.24 & -0.30 & 1.22 \\
Cyclical services & -0.05 & 2.45 & -0.51 & 4.27 \\
Non-cycl. Services & -0.06 & 1.61 & 0.01 & 0.68 \\
Utilities & -0.17 & 3.72 & 0.88 & 3.11 \\
Information technology & -0.28 & 4.07 & 0.93 & 6.46 \\
Financials & 0.18 & 4.34 & 0.50 & 3.01 \\
Others & 0.00 & 2.28 & -0.16 & 4.78 \\
Average & -0.51 & 2.79 & 0.21 & 2.62 \\
& -0.12 & 2.96 & 0.11 & \\
C. World: & & & & 0.79
\end{tabular}

Notes: This table reports descriptive statistics for the country, industry and global portfolios using the decomposition (2) subject to the constraints (3), (4). Returns are measured at the monthly frequency over the period February 1973 - February 2002 and are based on a data set covering up to 3,951 firms in developed stock markets. 


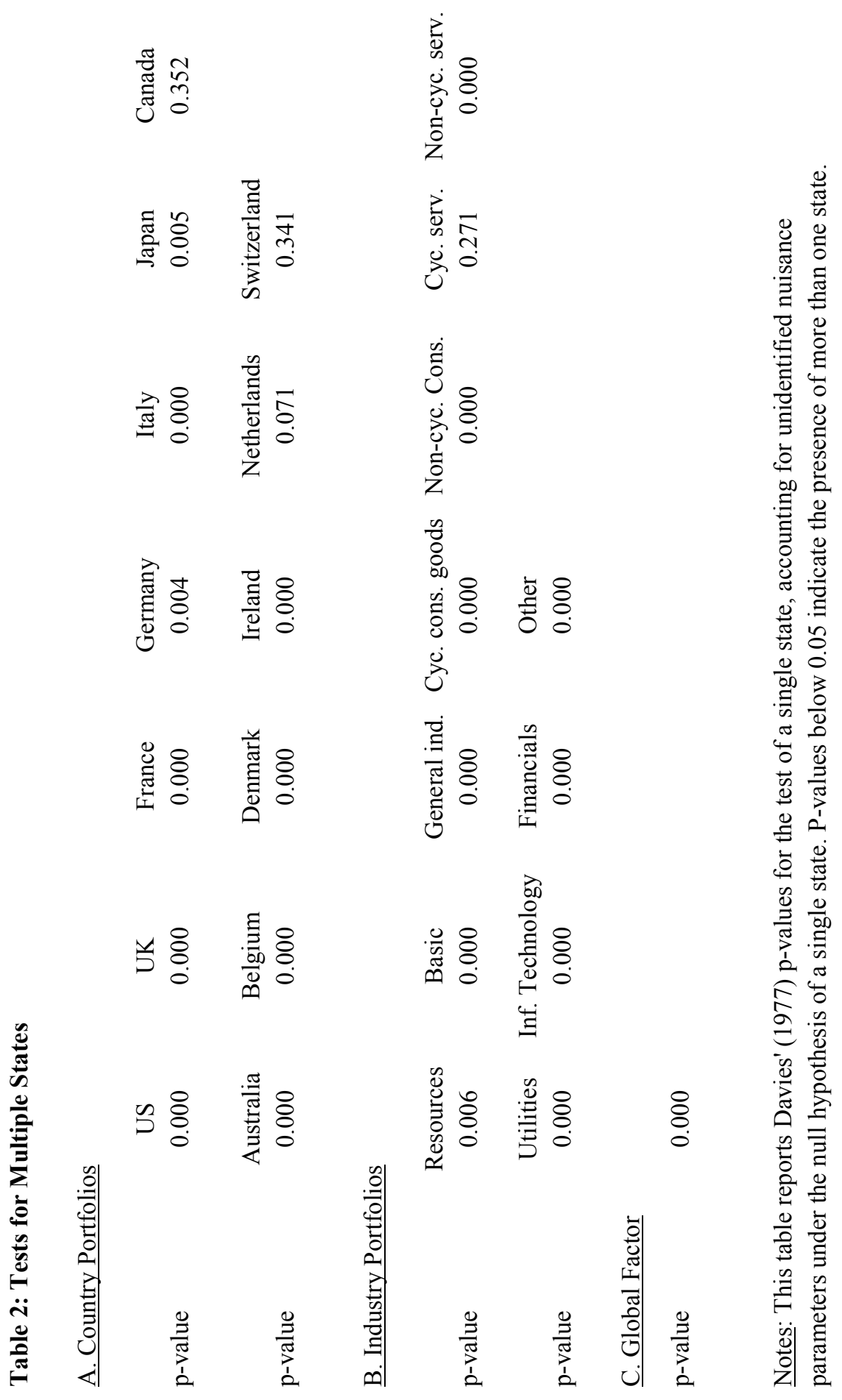




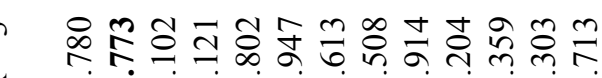

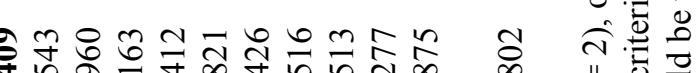

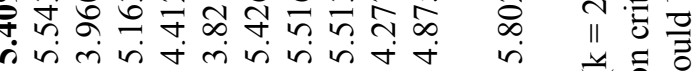

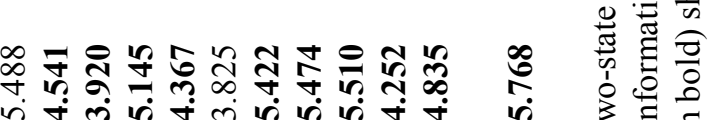

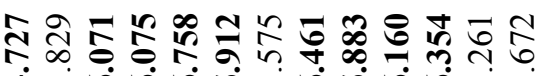

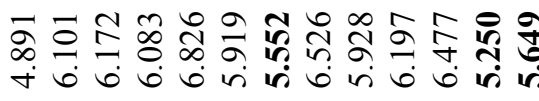

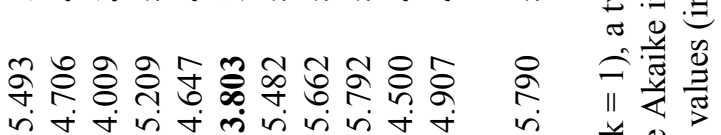

近范

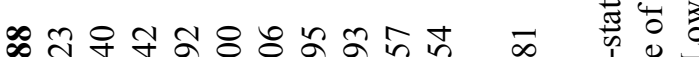

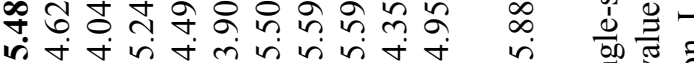

क

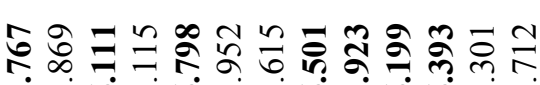

क人 की Й

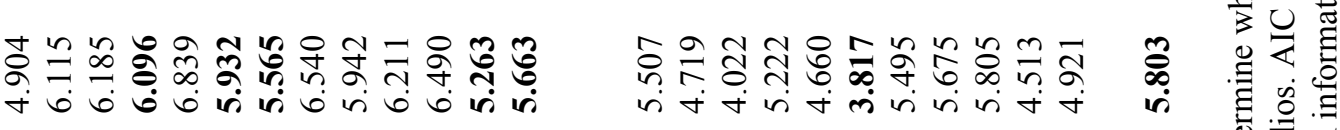

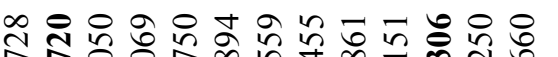

$\Rightarrow$ F

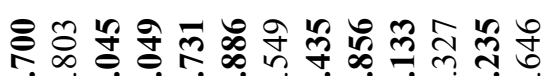

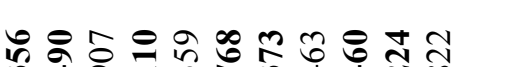

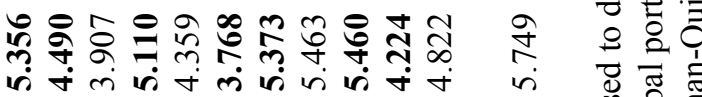

응

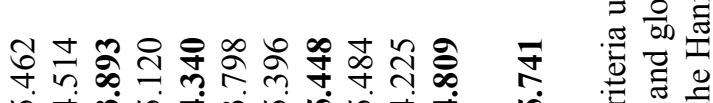

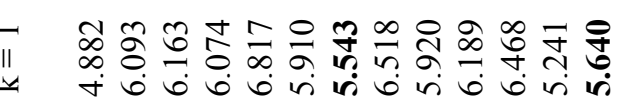

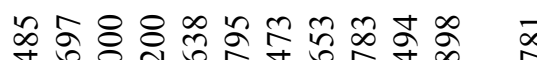

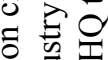

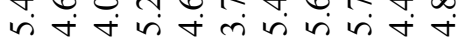




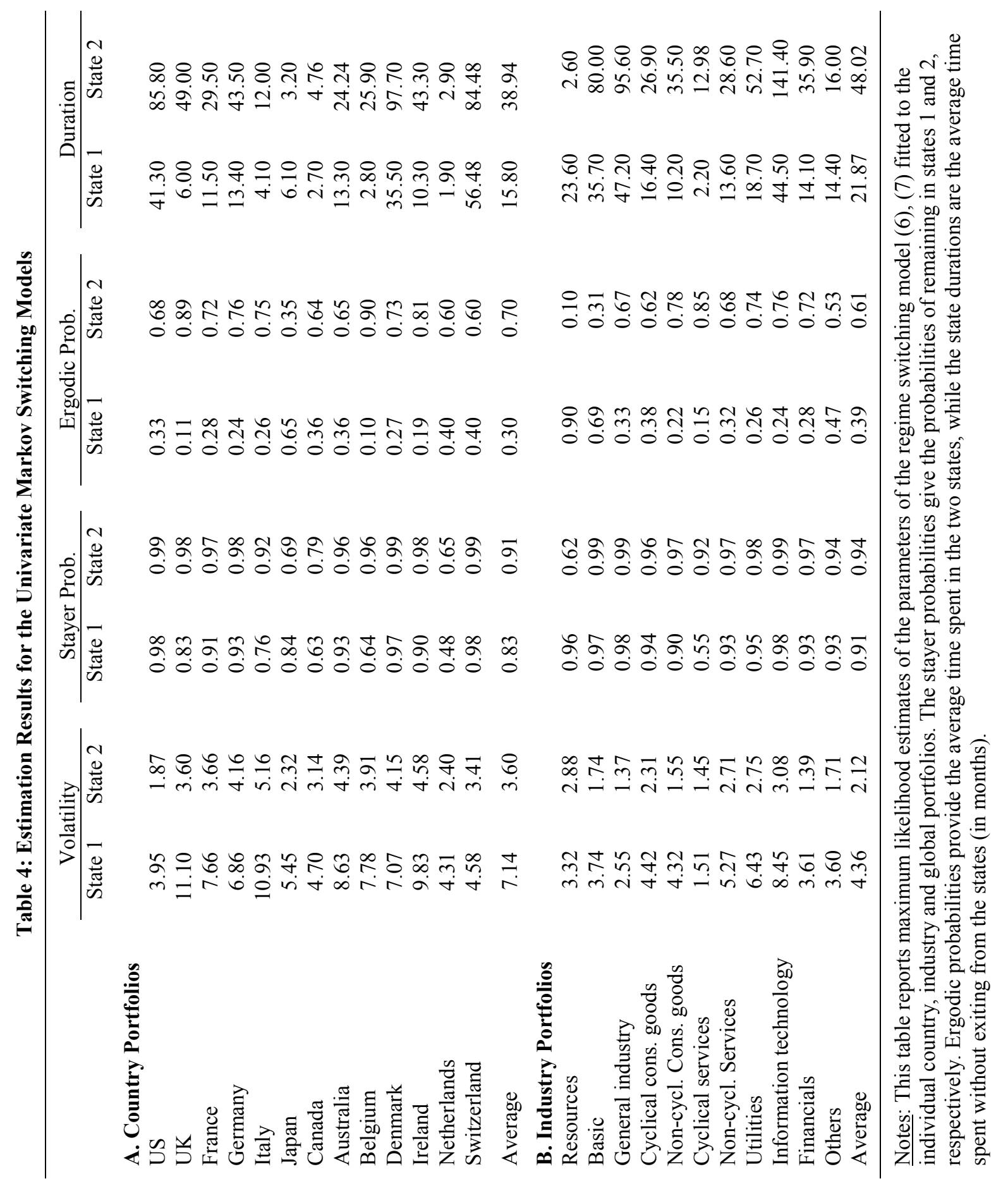




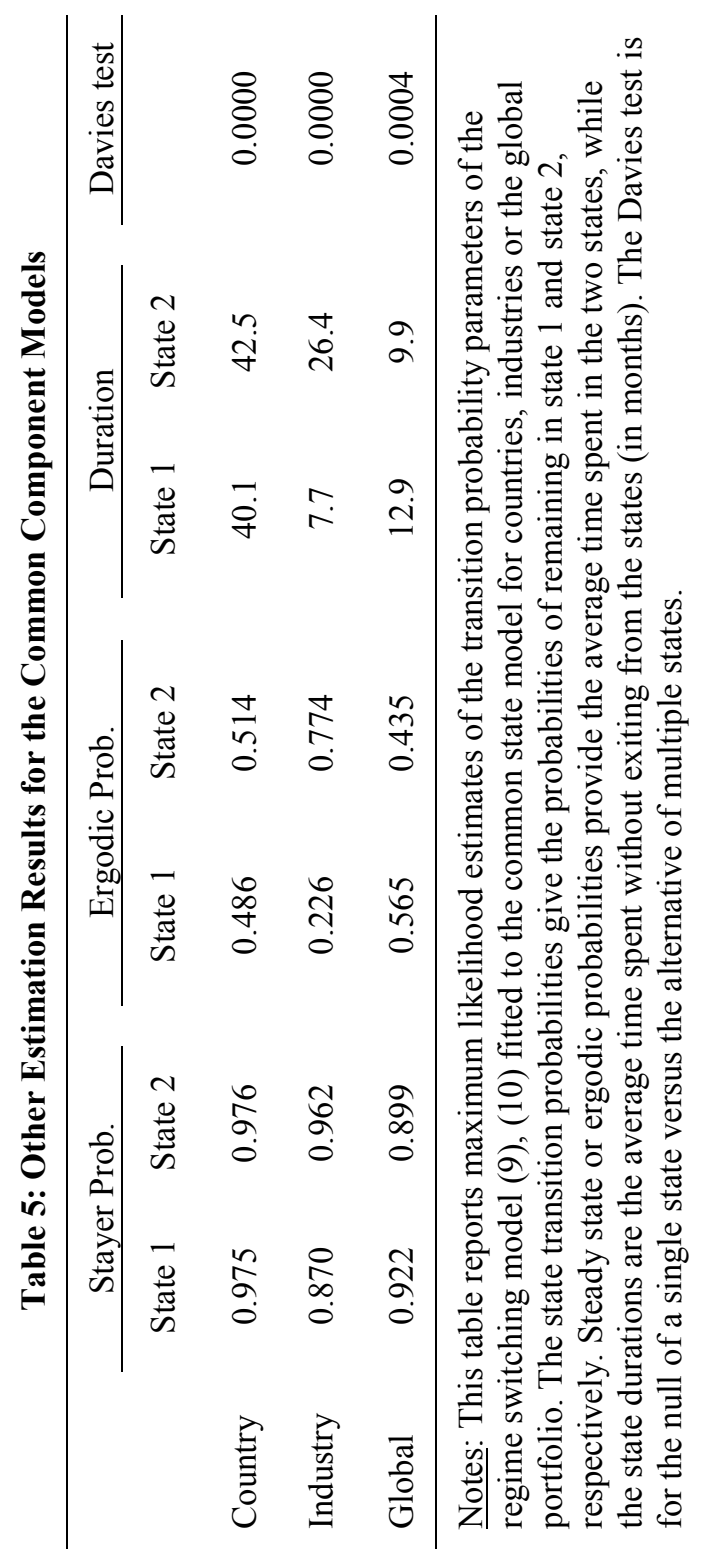




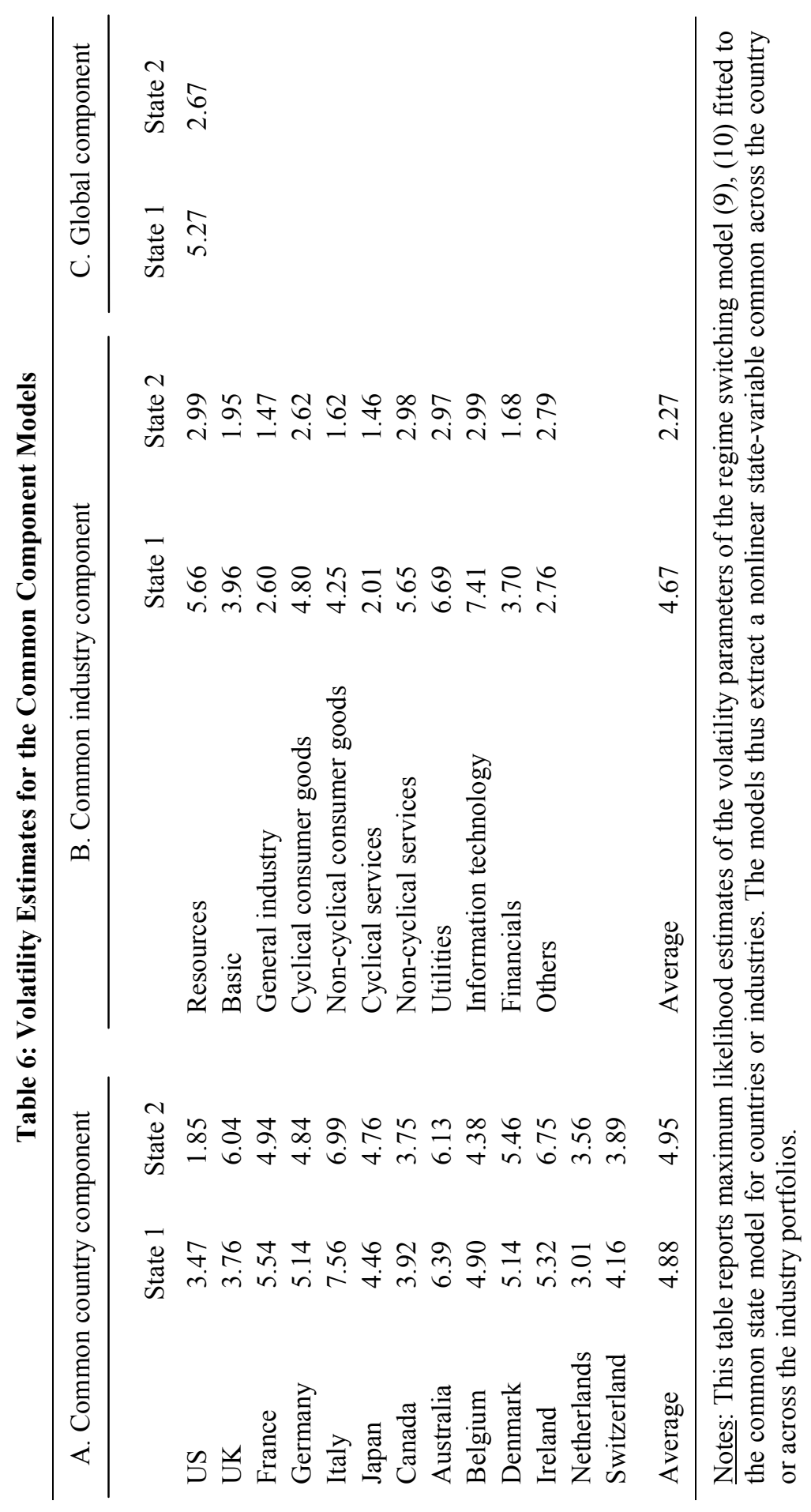


Table 7. Relative Contribution of "Pure" Country and Industry Factors to the Variance of Stock Returns

\begin{tabular}{ccccc}
\multicolumn{2}{c}{ High Industry Volatility State } & & Low Industry Volatility State \\
Pure Country Acc. Industry & & Pure Country Acc. Industry
\end{tabular}

$\underline{\text { A. Country Portfolios }}$

$\begin{array}{lllll}\text { US } & 0.955 & 0.091 & 0.992 & 0.011 \\ \text { UK } & 0.825 & 0.169 & 1.010 & 0.020 \\ \text { France } & 1.297 & 0.114 & 1.003 & 0.009 \\ \text { Germany } & 0.983 & 0.153 & 1.023 & 0.017 \\ \text { Italy } & 0.988 & 0.102 & 1.014 & 0.014 \\ \text { Japan } & 0.969 & 0.112 & 1.028 & 0.012 \\ \text { Canada } & 0.907 & 0.213 & 1.020 & 0.029 \\ \text { Australia } & 0.956 & 0.212 & 0.993 & 0.039 \\ \text { Belgium } & 1.092 & 0.300 & 1.028 & 0.033 \\ \text { Denmark } & 1.008 & 0.115 & 1.033 & 0.025 \\ \text { Ireland } & 0.922 & 0.227 & 1.053 & 0.026 \\ \text { Netherlands } & 0.626 & 0.471 & 0.973 & 0.107 \\ \text { Switzerland } & 0.971 & 0.438 & 1.033 & 0.049 \\ \text { Average } & 0.974 & 0.223 & 1.018 & 0.033\end{array}$

B. Industry Portfolios

$\begin{array}{lllll}\text { Resources } & 0.920 & 0.161 & 0.725 & 0.453 \\ \text { Basic } & 0.928 & 0.080 & 0.721 & 0.254 \\ \text { General industry } & 0.621 & 0.101 & 0.684 & 0.346 \\ \text { Cyclical cons. goods } & 1.168 & 0.114 & 0.941 & 0.309 \\ \text { Non-cycl. Cons. goods } & 0.772 & 0.138 & 0.435 & 0.532 \\ \text { Cyclical services } & 0.532 & 0.182 & 0.594 & 0.384 \\ \text { Non-cycl. Services } & 1.370 & 0.221 & 0.708 & 0.410 \\ \text { Utilities } & 1.345 & 0.060 & 0.894 & 0.200 \\ \text { Information technology } & 0.895 & 0.059 & 0.667 & 0.270 \\ \text { Financials } & 1.104 & 0.128 & 0.726 & 0.409 \\ \text { Others } & 0.349 & 0.647 & 0.511 & 0.923 \\ \text { Average } & 0.910 & 0.172 & 0.691 & 0.408\end{array}$

Notes: Panel A of this table shows the contribution of the "pure" country effect and the cumulated industry effect of the excess return (computed relative to the global return) on the individual country portfolios, using the decomposition (13) in the paper. Panel B shows the contribution of the "pure" industry effect and the cumulated country effect of the excess return (computed relative to the global return) on the individual industry portfolios using the decomposition (15) in the paper. The reported figures are ratios of the variance of each component to the variance of their sum (including their covariance). 


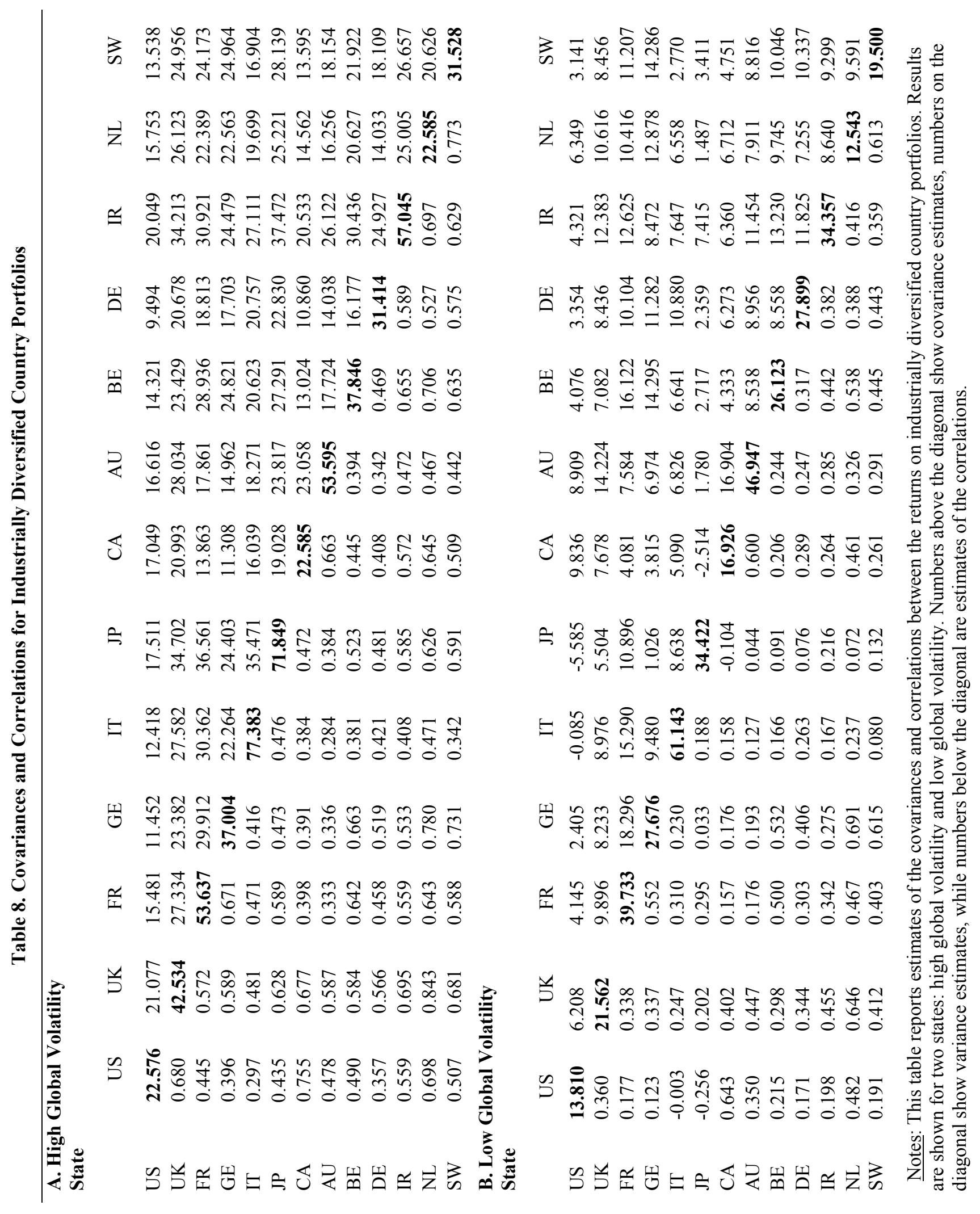




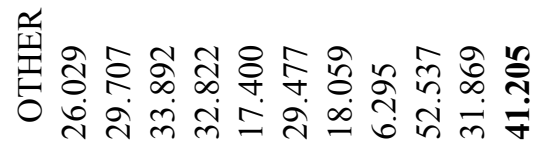

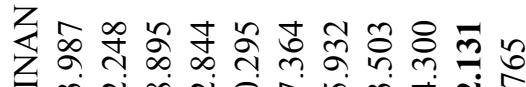

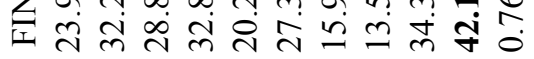

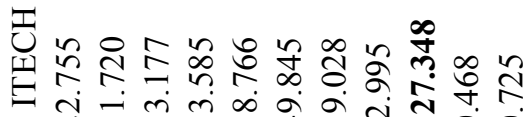

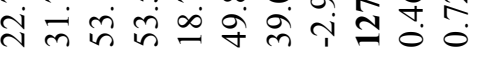

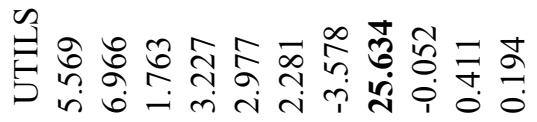

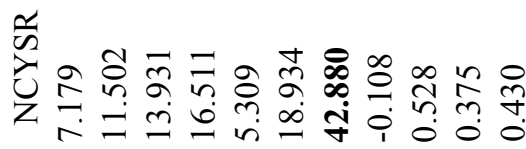

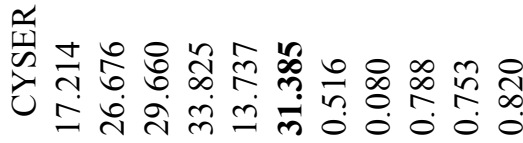

0

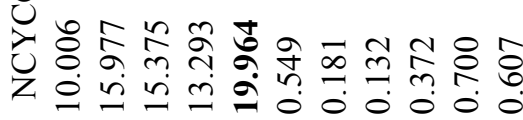

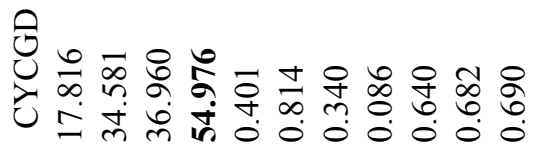



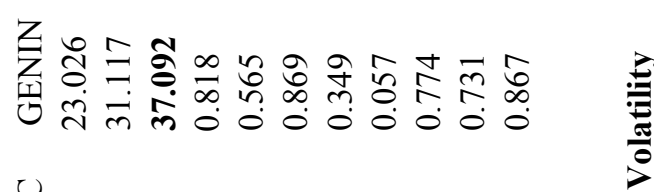

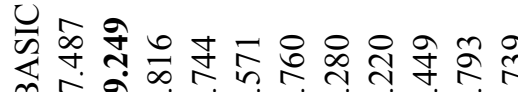

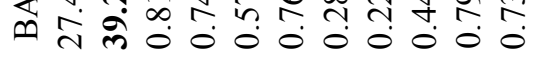

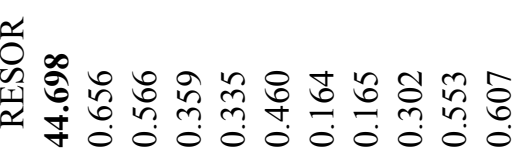

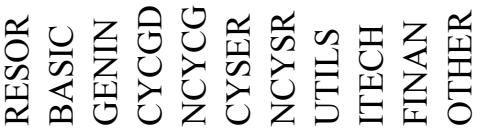

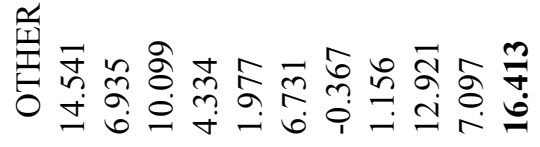

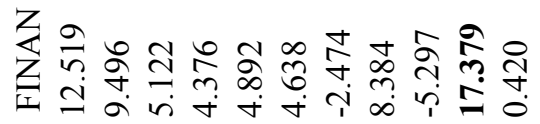

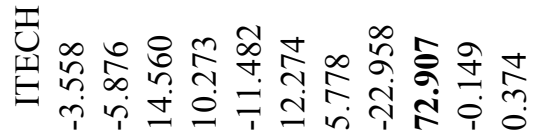

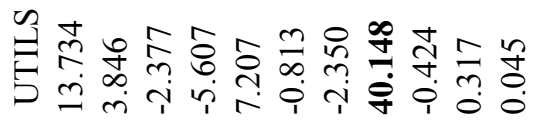

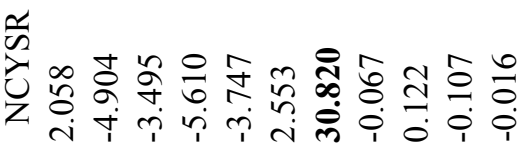

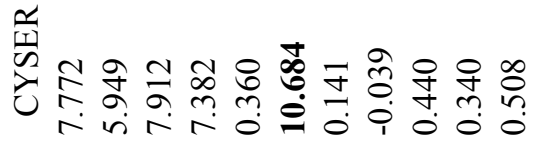

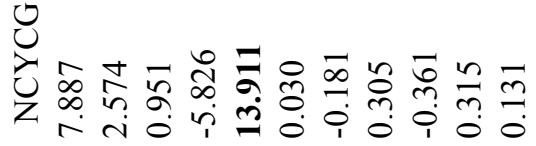

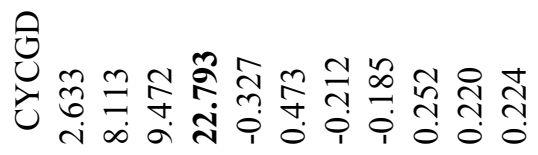

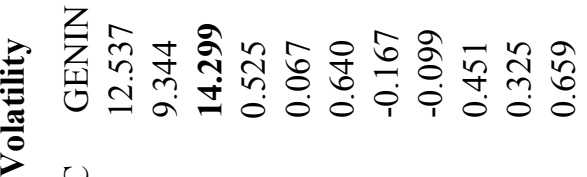

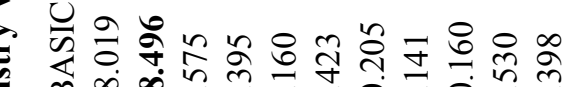

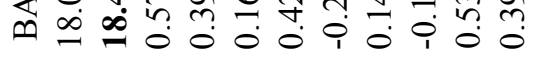

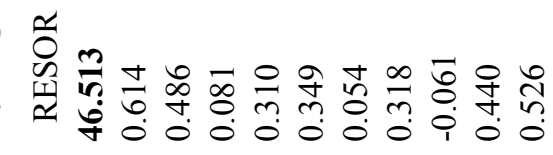

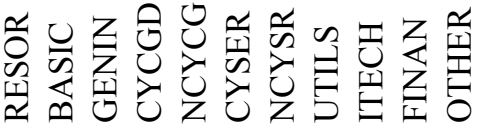




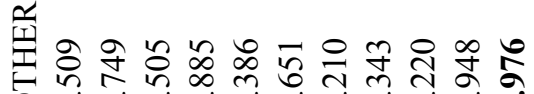

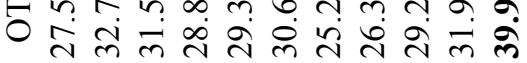

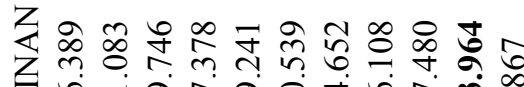

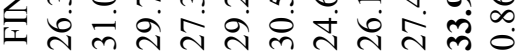

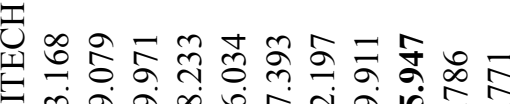

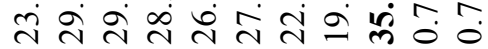

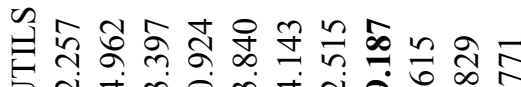

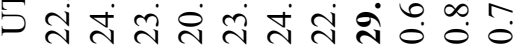

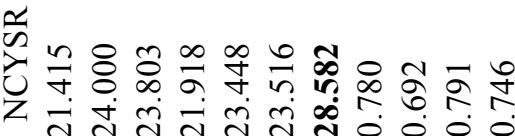

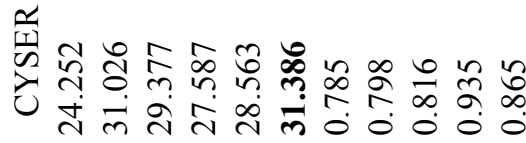

0

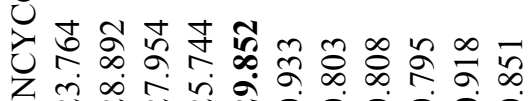

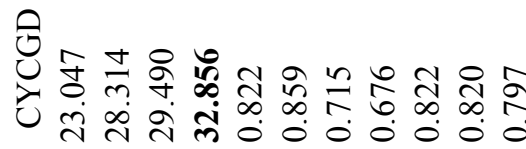

$\stackrel{1}{+\infty}$

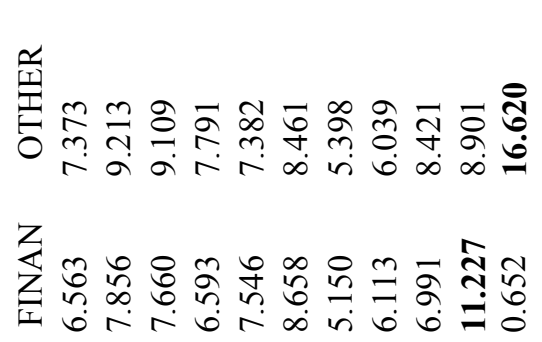

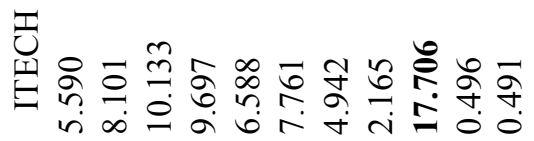

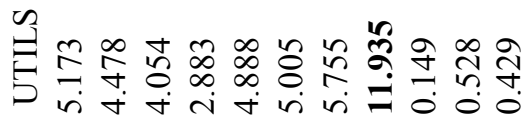

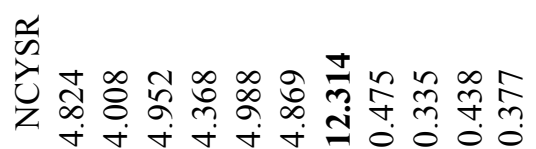

푯

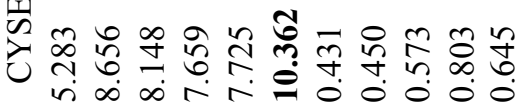

0

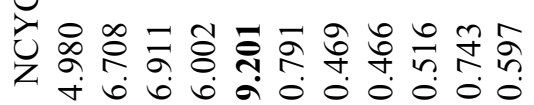

8

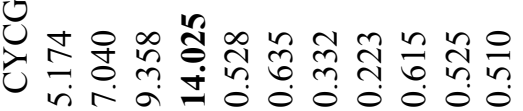

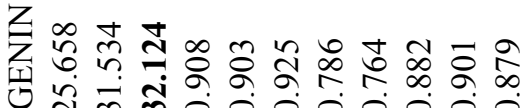

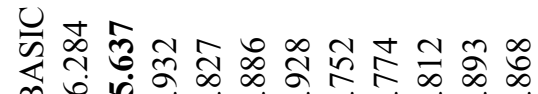

๓ $\underset{\sim}{m}$ ले

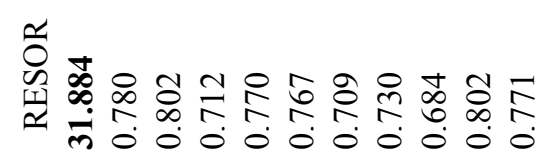

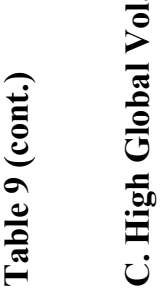

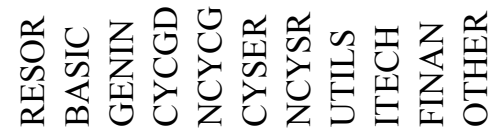

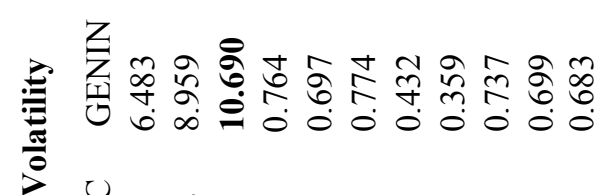

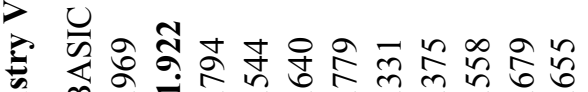

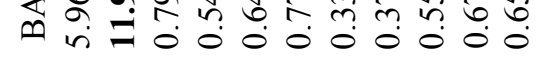

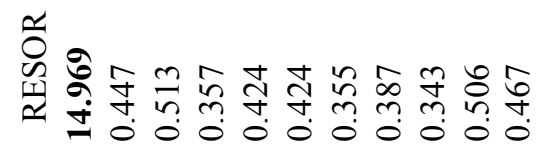

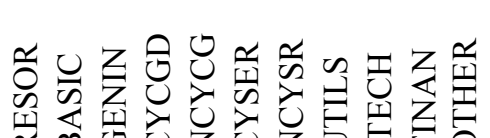

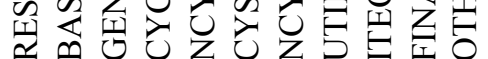

$\sum 0$

की 3 응

芯芯

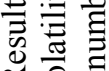

$\sim>$

离

का

之.

药

잉

तै 0

包

콣

ㄱㅇㅇㅇㅇㅇ

금

클

क्ञ⿰冫:

कo

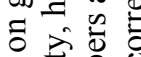

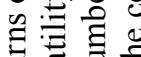

吾贾志

주

응

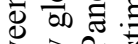

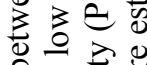

क

을

류 릅.

方昰

을롴

츨

웡으응

寻交心

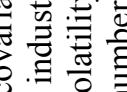

고요

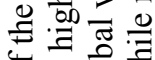

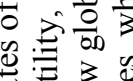

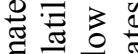

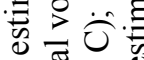

ก

후월

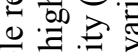

焉

.

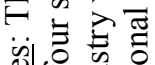

苞言 